HIAS-E-94

\title{
Decentralized Targeting of Agricultural Credit Programs: Private versus Political Intermediaries
}

\author{
Pushkar Maitra $^{(a)}$, Sandip Mitra ${ }^{(b)}$, Dilip Mookherjee ${ }^{(c)}$ and Sujata Visaria ${ }^{(d)}$ \\ (a) Department of Economics, Monash University, Clayton Campus, VIC 3800, Australia \\ (b) Sampling and Official Statistics Unit, Indian Statistical Institute, 203 B.T. Road, Kolkata 700108, India \\ (c) Department of Economics, Boston University, 270 Bay State Road, Boston, MA 02215, USA. \\ (d) Department of Economics, Lee Shau Kee Business Building, Hong Kong University of Science and \\ Technology, Clear Water Bay, Hong Kong
}

January, 2020

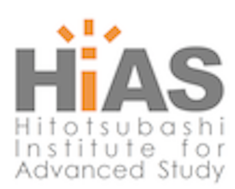

Hitotsubashi Institute for Advanced Study, Hitotsubashi University 2-1, Naka, Kunitachi, Tokyo 186-8601, Japan tel:+81 425808604 http://hias.hit-u.ac.jp/

HIAS discussion papers can be downloaded without charge from: http://hdl.handle.net/10086/27202

https://ideas.repec.org/s/hit/hiasdp.html

All rights reserved. 


\title{
Decentralized Targeting of Agricultural Credit Programs: Private versus Political Intermediaries*
}

\author{
Pushkar Maitra ${ }^{\dagger}$ Sandip Mitra $\ddagger$ Dilip Mookherjee, Sujata Visaria
}

January 2020

\begin{abstract}
We compare two different methods of appointing a local commission agent as an intermediary for a credit program. In the Trader-Agent Intermediated Lending Scheme (TRAIL), the agent was a randomly selected established private trader, while in the Gram Panchayat-Agent Intermediated-Lending Scheme (GRAIL), he was randomly chosen from nominations by the elected village council. More TRAIL loans were taken up, but repayment rates were similar, and TRAIL loans had larger average impacts on borrowers' farm incomes. The majority of this difference in impacts is due to differences in treatment effects conditional on farmer productivity, rather than differences in borrower selection patterns. The findings can be explained by a model where TRAIL agents increased their middleman profits by helping more able treated borrowers reduce their unit costs and increase output. In contrast, for political reasons GRAIL agents monitored the less able treated borrowers and reduced their default risk.
\end{abstract}

Key Words: Targeting, Intermediation, Decentralization, Community Driven Development, Agricultural Credit, Networks.

JEL Codes: H42, I38, O13, O16, O17

\footnotetext{
*Funding was provided by the Australian Agency for International Development, the International Growth Centre, United States Agency for International Development, the Hong Kong Research Grants Council (GRF 16503014) and the HKUST Institute for Emerging Market Studies (IEMS15BM05). We thank the director and staff of Shree Sanchari for collaborating on the project. Jingyan Gao, Arpita Khanna, Clarence Lee, Daijing Lv, Foez Mojumder, Moumita Poddar and Nina Yeung provided exceptional research assistance, and Elizabeth Kwok provided excellent administrative support. We thank audiences at numerous seminars and conferences for their comments and suggestions, which have significantly improved the paper. We received Institutional Review Board clearance from Monash University, Boston University and the Hong Kong University of Science and Technology. The authors are responsible for all errors.

${ }^{\dagger}$ Pushkar Maitra, Department of Economics, Monash University, Clayton Campus, VIC 3800, Australia. Pushkar.Maitra@monash.edu.

${ }^{\ddagger}$ Sandip Mitra, Sampling and Official Statistics Unit, Indian Statistical Institute, 203 B.T. Road, Kolkata 700108, India. Sandip@isical.ac.in.

${ }^{\S}$ Dilip Mookherjee, Department of Economics, Boston University, 270 Bay State Road, Boston, MA 02215, USA. dilipm@bu.edu.

『Sujata Visaria, Department of Economics, Lee Shau Kee Business Building, Hong Kong University of Science and Technology, Clear Water Bay, Hong Kong. svisaria@ust.hk.
} 


\section{Introduction}

Public programs in developing countries are increasingly being implemented at the local level. Communities are monitoring service providers, and local governments are delivering development and welfare programs. Despite the promise that decentralization can improve targeting and implementation through better information and accountability, a growing literature argues that these programs have a mixed record. ${ }^{1}$ Community-led programs are often captured by the local elite (see, for example World Development Report 2004; Mansuri and Rao 2013; Vera-Cossio 2018; Deserranno et al. 2018), and there is evidence that local governments target their vote bank, rather than those who stand to benefit the most (Stokes 2005; Robinson and Verdier 2013; Bardhan et al. 2015; Bardhan and Mookherjee 2016; Devarajan and Khemani 2016; Dey and Sen 2016).

In this paper we present evidence on a new alternative designed in the context of an agricultural credit program in West Bengal, India. The program offered subsidized individual liability loans to smallholder farmers. Our approach, called Agent Intermediated Lending (AIL), delegates the selection of beneficiaries to an intermediary chosen from within the community. It sought to leverage the intermediary's specialized information and connections with local residents, while avoiding the pitfalls associated with elite capture.

During 2010-2013 we collaborated with a microfinance institution that implemented the AIL scheme in 48 randomly chosen villages in two potato-growing districts of West Bengal, India. We experimented with two different versions of the AIL scheme. ${ }^{2}$ In the 24 villages randomly assigned to the Trader-Agent Intermediated Lending (TRAIL) treatment, the agent was randomly chosen from a list of local private traders with a track record of lending to, and selling and buying from farmers in the village. In the remaining 24 villages assigned to the Gram Panchayat Agent Intermediated Lending (GRAIL) treatment, the agent was randomly selected from a list of local individuals provided by the elected village council in GRAIL. The agents then recommended village households for individual liability loans designed to finance the cultivation of the local

\footnotetext{
${ }^{1}$ In her survey of community-driven development (CDD) programs around the world, Casey (2018) argues that although CDDs have successfully provided public goods in countries with weak states (for example, Sierra Leone, Indonesia, Afghanistan and Sudan), they have generally failed to transform local decision-making or increase empowerment.

${ }^{2}$ In a different set of 24 randomly chosen villages in the same districts, we implemented a group-based lending (GBL) approach, where borrowers self-selected into joint liability groups. Our previous research (Maitra et al. 2017) compares TRAIL with GBL. In the current paper we focus on a comparison of the TRAIL and GRAIL schemes.
} 
cash crop, potatoes. They earned as commission 75 percent of the interest payments made by each borrower they recommended. ${ }^{3}$

The goal of this paper is to evaluate these alternative methods of devolution of beneficiary selection. Specifically, we ask if the programs had positive impacts on farmer cultivation decisions, output and incomes. We examine whether the impacts differ across the two approaches, and why. In particular, the agent's identity, networks and motivations could have affected the success of the intervention. Given their experience lending and trading farm inputs and output within the community, the TRAIL agents may be better informed about borrowers' farm productivity and reliability. They could also expect to earn middleman profits from trading the farmers' output, and so may have chosen to direct credit and business advice to their most productive farmer-clients. ${ }^{4}$ GRAIL agents, on the other hand, would have likely acted in line with the priorities of their political party, for example, selecting poor beneficiaries to further their party's pro-poor agenda. They may also have been motivated differently vis-a-vis their beneficiaries' projects: they were unlikely to benefit directly if their borrowers had large harvests, and instead could have faced the blame if the borrowers' projects failed and they fell into economic distress. The agents would also likely impose informal sanctions on defaulting borrowers. A TRAIL agent might withhold future business transactions, and the GRAIL agent might apply social or political pressure.

Our experimental design allows us to separate the effect of receiving an AIL loan from the confound caused by endogenous borrower selection. In each village, the agent was asked to recommend 30 village residents as potential borrowers, but only 10 randomly chosen from this list were offered the AIL loan. Among the recommended, a comparison of those who were offered the loan with those who were not, provides an estimate of the treatment effect of the loan, conditional on selection. Among those who were not offered the loans, the underlying differences between those who were and were not recommended allow us to separately estimate the selection effect.

Our estimates show that TRAIL loans were more likely to be taken up than GRAIL loans. Among the loans taken up, repayment rates were a similarly high 93 percent in both schemes. In both schemes, beneficiaries borrowed more, cultivated more area and had larger potato harvests. However, potato profits and farm incomes only increased for

\footnotetext{
${ }^{3}$ See Fuentes (1996), Varghese (2005) and Mansuri (2007) for theoretical arguments about credit delivery using local agents and bank-money-lender linkages in developing countries.

${ }^{4}$ The potato value chain in this region is characterized by large middlemen margins: Mitra et al. (2018) estimate that in 2008 farmgate prices were $45 \%$ of wholesale prices, with middlemen earning at least $50-70 \%$ of this gap.
} 
beneficiaries in the TRAIL scheme (by 40 percent and 21 percent, respectively). ${ }^{5}$ This is because TRAIL farmers' expansion of cultivation was accompanied by a reduction in unit production costs, whereas GRAIL farmers continued to produce at previous (high) costs per acre.

We develop a simple model with a decreasing returns Cobb-Douglas production function where farmers vary in a single productivity attribute, and at baseline, the allocation of informal credit is efficient. We use this model to estimate farmer productivity, and find that the TRAIL agent selected more productive farmers than the GRAIL agent did. And yet, this selection difference accounts for less than 10 percent of the TRAIL-GRAIL difference in the average treatment effects on farm income. We show that alternative explanations such as superior selection on other farmer attributes (such as wealth or unit costs), and credit rationing cannot explain why the TRAIL scheme outperforms the GRAIL. Instead, our analysis indicates that most of the difference can be attributed to the TRAIL scheme generating larger treatment effects on farm income, conditional on farmer productivity. Specifically, our findings suggest that a beneficiary in the TRAIL scheme produced more output at significantly lower per-unit cost and earned larger profit, than a GRAIL beneficiary of the same productivity. Since the loan product and hence borrower incentives were identical in the two schemes, this suggests that the key difference was the borrower's relationship with their agent.

Accordingly, we extend our simple model of selection on a single productivity dimension to incorporate interactions between agents and borrowers. Since TRAIL agents are also middlemen in the potato trade, they are motivated to increase their profits by helping their clients produce and sell more(Mitra et al. 2018). In our model, they advise farmers on ways to lower unit costs of production, inducing them to cultivate more potatoes, and earn larger profits per kilogram. This advice is most effective for the most able farmers. On the other hand, the GRAIL agent is motivated by the objectives of the political party controlling the village council. His primary goal is to minimize loan defaults, and accordingly he may intensively monitor poor, less able borrowers and induce them undertake actions and expenditures that ensure crop success, but also lower expected profits. As a result GRAIL borrowers would incur higher costs than TRAIL borrower. We show that our model's predictions match empirical patterns in default rates and conditional treatment effects on borrowers' farm output and incomes, as well as the frequency of their interactions with the agent and local traders.

\footnotetext{
${ }^{5}$ These percentage effects are mirrored in the absolute effects on borrower profits and farm incomes, since control farmers in both schemes had similar profits and incomes.
} 
Our paper contributes to the recent literature that examines the role that community agents play in development interventions. Several recent papers find that central individuals in the network can help to effectively target beneficiaries, diffuse information and increase program take-up (Bandiera and Rasul 2006; Alatas et al. 2012, 2016; Fisman et al. 2017; Hussam et al. 2018; Berg et al. 2018; Beaman and Magruder 2012; Debnath and Jain 2018; Beaman et al. 2018; Banerjee et al. 2013; Chandrasekhar et al. 2018). We bring to this literature the observation that villages tend to have a number of different networks: economic, political and social. The nodal agents of different networks may have different information sets and different incentives to deliver development programs. This raises the question of which network to tap into. Further, the intervention itself may affect network relationships, and thereby also affect borrowers' profits. Our results indicate the importance of looking beyond the architecture of local networks, and incorporating the effects of policy treatments on relationships within the network. Our work also sheds light on the specific role that intermediaries play. ${ }^{6}$ We provide evidence on interactions between the beneficiary and program intermediary, and quantify the importance of such interactions vis-a-vis beneficiary selection.

Our experiment provides a rare instance of a microcredit experiment that successfully raised borrower production and incomes, while maintaining high repayment rates and take-up. In a previous paper (Maitra et al. 2017), we found that the TRAIL scheme also outperformed a traditional group-based micro-lending (GBL) scheme. We found that differences in borrower selection accounted for at least 30-40\% of the difference in the average treatment effects across the two schemes. Instead, this paper finds that selection differences explain very little of the difference in the outcomes of the TRAIL and GRAIL schemes; accordingly we focus on the role of interactions between the agent and farmers. ${ }^{7}$ Interestingly, the large profits that the traders earn as middlemen appear to be the precise reason why their incentives are aligned with increasing farmers' output.

The paper is organized as follows. In Section 2 we describe the two loan intervention schemes that we will analyse in this paper. Section 3 describes our data and Section 4

\footnotetext{
${ }^{6}$ For example, Beaman and Magruder (2012) argue that members of social networks can be incentivized to help select and refer high ability workers to jobs. On the other hand, Heath (2018) finds evidence that firms mitigate shirking by workers referred by employees that interact with them socially, relying on these interactions to help weaken the effect of limited liability constraints.

${ }^{7}$ In another related paper (Maitra et al. 2019), we compare the distributive effects of TRAIL, GRAIL and GBL, by assessing their impacts on an Atkinson (1970) welfare function. We find that the TRAIL scheme had significantly positive average treatment effects on welfare that were consistently larger than the average treatment effects of the GRAIL and GBL schemes, irrespective of the degree of inequality aversion.
} 
presents the estimates of the average treatment effects of the two schemes on borrower outcomes. In Section 5 we present statistics on the financial performance of the schemes. To explain our empirical findings, in Section 6 we examine how and why selection patterns varied across the two schemes. We then decompose the difference in average treatment effects into the part that can be explained by these selection differences, and the part that is due to differences in the treatment effects, conditional on borrower productivity. Since we find that this latter part is substantial, in Section 7 we develop a model of agent incentives and agent-farmer interactions and test its predictions. Section 8 concludes.

\section{Empirical Context and Intervention Design}

Our interventions were conducted across 48 randomly-chosen villages in the Hugli and West Medinipur districts of the Indian state of West Bengal. ${ }^{8}$ The loans offered through the AIL schemes were designed to facilitate the cultivation of potatoes, a high return high-cost crop in this region (see Maitra et al. 2017, Table 2).

The 48 villages in our sample were randomly and evenly assigned to the two treatment arms. Our sample villages were at least 8 kilometres apart from one another; this helped to avoid information and other spillovers across the treatment arms. Each village belonged to the jurisdiction of a different village council or gram panchayat (GP). Panel A of Table 1 shows that across the villages in the two treatment arms there are no significant differences in village size, or number or landsize distribution of potato cultivators. Our partner MFI had not operated in any of these villages before. In general, when our intervention began in 2010, there was very little microfinance available in this area.

The institutional arrangements in this region are such that potato traders regularly visit farmers in their fields, and often engage in repeated sales and credit transactions with farmers. In each TRAIL village, our project team drew up a list of local traders who had at least 50 clients or had been operating for longer than 3 years. One trader was randomly drawn from this list and offered the position of agent. ${ }^{9}$

In India, gram panchayats are village councils of between 8 and 15 members, formed through direct elections once every five years. In the West Bengal village councils,

\footnotetext{
${ }^{8}$ This is a subset of the random sample of villages where Mitra et al. (2018) conducted a potato price information intervention experiment in 2007-08.

${ }^{9}$ If this person had refused to participate, we would have offered the position to a second randomly chosen trader from the list. In practice the first trader approached always accepted the contract.
} 
candidates tend to be affiliated with state-level political parties. ${ }^{10}$ Many government schemes are implemented locally by village councils, and local party affiliates are often involved in both identifying beneficiaries and delivering benefits. ${ }^{11}$

In the villages assigned to the GRAIL treatment, we asked the village council to suggest as potential GRAIL agents individuals who had lived in the village for at least 3 years, were personally familiar with village farmers, and had a good local reputation. Given the background we described above, we expected the GP to recommend political affiliates experienced at delivering government benefits. One randomly drawn person from this list was offered the contract. ${ }^{12}$

In each intervention arm, the agent was asked to recommend 30 potential borrowers, from the land-poor households in the village. ${ }^{13}$ Ten of these 30 recommended individuals were randomly chosen in a lottery that we conducted in the office of the local government. ${ }^{14}$ The MFI then approached the selected individuals in their homes and offered them the loans.

Our partner MFI was limited to disbursing hte program loans and collecting repayment. It did not select borrowers or monitor them subsequently. The loans were funded through an external grant held by the principal investigators of this project.

The first loan cycle began with disbursals in October-November 2010, to coincide with the planting season for potatoes. Borrowers were individually liable for the repayment of their loans. The scheme featured "progressive lending" to generate dynamic repayment incentives. In cycle 1 the loan size was capped at Rs. 2000 (equivalent to US \$30), repayable as a single lumpsum at the end of four months, at 6 percent interest. The loan size in each subsequent cycle was $133 \%$ of the principal amount repaid. Borrowers who repaid less than $50 \%$ of principal in any cycle, were terminated. We did not

\footnotetext{
${ }^{10}$ West Bengal has a long history of cadre-based mass mobilization of voters through political rallies and campaigns. From 1977 to 2011, the Communist Party of India (Marxist) led a left-wing coalition government in West Bengal state, and held the majority of the village council seats. This long dominance ended when the Trinamool Congress captured the majority of state assembly seats in the 2011 state elections. After the 2013 village council elections most village councils also had a Trinamool Congress majority.

${ }^{11}$ There is considerable evidence that local governments in West Bengal direct benefits towards swing voters (Bardhan et al. 2015; Dey and Sen 2016).

${ }^{12}$ Only 1 of the 24 individuals selected in this way refused the position, citing a religious taboo on participating in a credit scheme. He was replaced by a second randomly drawn person from the list.

${ }^{13}$ Specifically, we required that recommended households owned no more than 1.5 acres of cultivable land.

${ }^{14}$ The list of recommended borrowers was kept confidential so as to avoid any spillovers on informal credit access or other relationships for households that had been recommended but were not eventually chosen to receive the loan.
} 
want to create any pressure for borrowers to sell their harvest prematurely to meet their repayment obligation; therefore borrowers could also repay in potato "bonds"; we then calculated the rupee value of the repayment at the prevailing price of potato bonds. ${ }^{15}$ Although the stated purpose of the loans was agricultural, we did not monitor or restrict how households spent the funds. ${ }^{16}$

Agents had both monetary and non-monetary incentives to participate in the scheme. At the end of each loan cycle, they received from the MFI a commission equal to $75 \%$ of the interest paid by all borrowers whom they had recommended. This high commission rate was meant to incentivize the agent to select productive borrowers who would repay the loan and benefit from it, and to discourage collusion between the agent and potential applicants. ${ }^{17}$ In addition, the agent put down a deposit of Rs. 50 per borrower, which was refunded if his borrower survived in the program for two years. If more than onehalf of the borrowers recommended by an agent defaulted on their loans, the agent was terminated and earned no further commissions. All agents who survived in the program for 2 years also received a paid holiday to a seaside resort. In conversations during our field visits, some TRAIL agents remarked that they expected the scheme to increase their prominence in the village, or to boost their business. GRAIL agents may also have viewed the scheme as an extension of government anti-poverty programs, or expected the public to view their political party more favorably because of association with the scheme.

\section{Data and Selected Descriptive Statistics}

We conducted surveys with a sample of 50 households per village. These households were selected as follows. In each village, all 10 households assigned to receive the loan (Treatment households) were included in the sample. Of the 20 households that the agent recommended but did not receive the loan, we included a random subset of 10 households; they are referred to as Control 1 households. We also included 30 households randomly chosen from the pool of the non-recommended, hereafter referred to as Control 2 households.

The first round of surveys was conducted in December 2010, two months after the

\footnotetext{
${ }^{15}$ Farmers can store their harvest in cold storages for a maximum of 11 months. Potato "bonds" are receipts from the cold store facility that are often traded between farmers and traders.

${ }^{16}$ Survey respondents reported to us their actual use of loan funds in our detailed four-monthly household surveys.

${ }^{17}$ Maitra et al. (2017) presents a model of borrower selection that illustrates this mechanism.
} 
Cycle 1 loans were disbursed. Surveys were repeated every four months. In each sample household, we ensured that the same person responded to the survey in each round. There was no attrition in the sample over the eight survey rounds. In Panel B of Table 1, we present summary statistics of selected household-level characteristics for this sample. These household characteristics do not jointly explain assignment to treatment $(p=0.996)$.

Table 2 compares the characteristics of the TRAIL and GRAIL agents. Over $95 \%$ of the TRAIL agents were business persons and reported owning a shop or business. GRAIL agents were either farmers, or had a salaried government job. TRAIL agents were wealthier and had higher incomes, but were less likely to have studied beyond primary school. On the other hand GRAIL agents were more involved in civil society and politics; $30 \%$ were members of a village organization, $17 \%$ were political party workers, and $13 \%$ had been members of the local government. None of the TRAIL agents were directly involved in politics in this way.

Table 3 presents information about the relationships between agents and village residents. Both types of agents were well-known in the village. More than $90 \%$ of the non-recommended Control 2 households said they knew the agent, and $98 \%$ of these 90 percent said they saw him at least once a week. However Control 2 households were less likely to have close social ties with the agent, as depicted by belonging to the same caste or religious category, or visiting the agent's house on special occasions.

The main distinction between TRAIL and GRAIL agents is in their economic links with sample households. Nearly a fifth of Control 2 households and a quarter of Control 1 households in TRAIL villages reported that the agent was an important source of credit or inputs, or an important buyer of their crop output. The GRAIL agent was significantly less likely to fill these roles. ${ }^{18}$ In survey round 1 in December 2010, we also asked households whether they had transacted with the agent in the product, credit or labour markets at any point in the previous three years. A third or more of TRAIL households had bought from the agent, and a tenth to a quarter had borrowed or worked for the agent. Households in GRAIL villages were less likely to have engaged with their agent in this way. This suggests that the TRAIL agents were better informed about the cultivation and borrowing activities of village residents.

Table A1 in the Appendix summarizes the characteristics of the loans that sample households held at the time that our intervention began. Two-thirds of the households

\footnotetext{
${ }^{18}$ We note however that about $10 \%$ of sample households in both treatment arms reported that they had worked for the agent.
} 
reported that they had an outstanding loan, the bulk of which were for production purposes. Of the agricultural borrowing, nearly two-thirds was from traders or moneylenders, for a mean duration of 4 months and an average annual interest rate of $25 \%$. Credit cooperatives accounted for nearly one quarter of the loans, but loans from commercial banks and from microfinance institutions were rare. Cooperatives and commercial banks charged much lower interest rates, but generally required collateral, and so were inaccessible to poor households.

\section{Average Treatment Effects of the Schemes}

We start by examining the impacts of the TRAIL and GRAIL schemes on borrower outcomes. Since only a random subset of the recommended household were offered the loans, the average difference in the outcomes of the Treatment and Control 1 households is an estimate of the treatment effect of the loan, conditional on the household being selected into the scheme. The average difference in the outcomes of the Control 1 and Control 2 households is an estimate of the selection effect. Our regression specification takes the form:

$$
\begin{aligned}
y_{i v t} & =\beta_{0}+\beta_{1} \text { TRAIL }_{v}+\beta_{2}\left(\text { TRAIL }_{v} \times \text { Control } 1_{i v}\right)+\beta_{3}\left(\text { TRAIL }_{v} \times \text { Treatment }_{i v}\right) \\
& +\beta_{4}\left(\text { GRAIL }_{v} \times \text { Control } 1_{i v}\right)+\beta_{5}\left(\text { GRAIL }_{v} \times \text { Treatment }_{i v}\right) \\
& +\gamma \mathbf{X}_{i v}+I\left(\text { Year }_{t}\right)+\varepsilon_{i v t}
\end{aligned}
$$

Here $y_{i v t}$ denotes the outcome variable of interest for household $i$ in village $v$ at time $t$. The omitted category is the Control 2 households in GRAIL villages. The average treatment effects of the TRAIL and GRAIL schemes are estimated by $\hat{\beta}_{3}-\hat{\beta}_{2}$ and $\hat{\beta}_{5}-\hat{\beta}_{4}$ respectively. ${ }^{19}$ The coefficient $\hat{\beta}_{2}$ is the difference in outcomes of Control 1 and Control 2 borrowers in TRAIL villages, and so represents the TRAIL selection effect; analogously, $\hat{\beta}_{5}$ measures the GRAIL selection effect. The set $\mathbf{X}_{i v}$ contains measures of the household's landholding, religion and caste, and the age, education and occupation of the oldest male in the household. ${ }^{20} I\left(\right.$ Year $\left._{t}\right)$ denotes two year dummies to control for

\footnotetext{
${ }^{19}$ All treatment effects are intent-to-treat estimates because they compare the outcomes of households assigned to the Treatment and Control 1 groups, regardless of whether the Treatment households actually took the loan.

${ }^{20}$ In our study the administrative definition of a village corresponds to a collection of hamlets or paras. Households within the same hamlet tend to be more homogenous, are more likely to interact with each other, and arguably experience correlated shocks to cultivation and market prices. The results are
} 
secular changes over time. ${ }^{21}$ Standard errors are clustered at the hamlet level.

\subsection{Treatment Effects on Agricultural Borrowing}

Columns 1 and 2 of Table 4 present the average treatment effects on agricultural borrowing. The TRAIL scheme increased total agricultural borrowing for selected households by Rs. 2868 (or 137\%) over the three-year study period, which is statistically significant at the $1 \%$ level. The GRAIL scheme caused a similar, significant, increase of Rs. 2754 (or 143\%). The point estimates on non-program agricultural borrowing are small and statistically insignificant, suggesting that the TRAIL and GRAIL loans did not crowd out agricultural loans from other sources. Thus Treatment households took the additional subsidized credit, but did not substitute away from their more expensive pre-existing informal loans, possibly because they wanted to sustain their traditional informal credit relationships.

\subsection{Treatment Effects on Farm Incomes}

Columns 3, 4 and 5 of Table 4 present the estimates of average treatment effects on aggregate farm and non-farm income. In column 3, farm value-added is computed as the sum of the value-added for the four major crops grown in this region: potatoes, paddy, sesame and vegetables. ${ }^{22}$ The TRAIL loans caused a statistically significant $21 \%$ increase in average farm value-added, whereas GRAIL loans had a non-significant impact, estimated at $1.3 \%$. In column 4 , non-agricultural income is calculated as the sum of rental, sales, labour and business income. The average treatment effect estimates for non-agricultural income are imprecise, possibly because these incomes are measured with greater error. Nevertheless, column 4 indicates that neither loan scheme increased non-agricultural incomes significantly. Column 5 shows that aggregate income increased by $11.3 \%$ in the TRAIL scheme, and decreased by $10 \%$ in the GRAIL scheme; this difference is statistically significant at the $10 \%$ level.

robust to clustering at the village-level instead. See Panel B of Table A3.

${ }^{21}$ In Panel A of Table A3 we present the results from running equation (1) without the set of controls $\mathbf{X}_{i v}$. The key effects are qualitatively similar, although less precise.

${ }^{22}$ The separate results for paddy, sesame and vegetables are available on request. 


\subsection{Treatment Effects on Potato Cultivation}

Recall that the AIL loans were designed specifically to enable the cultivation of potatoes, the highest-value cash crop in the region. Table 5 shows that the TRAIL loans led to large and statistically significant increases in potato cultivation. ${ }^{23}$ The effect is concentrated on the intensive margin: although the TRAIL Treatment households were just as likely to cultivate potatoes as the Control 1 households (column 1), they planted an additional 0.09 acres (or 27\%, column 2), harvested $950 \mathrm{~kg}$ (or 26\%, column 3) more, and earned an additional Rs. 3900 (or $27 \%$, column 5) in sales revenue. ${ }^{24}$ Simultaneously they incurred an additional Rs. 1846 (or $22 \%$, column 4) in production costs, so that on net, value-added increased by Rs. 2060 (or 36\%, column 6). When we subtract the imputed cost of family labor, this works out to a statistically significant Rs. 1907 or $40 \%$ increase in profit (column 7 ). ${ }^{25}$

The households that the GRAIL agent recommended were less likely to cultivate potatoes in the absence of the loan: potatoes were planted in only $64 \%$ of Control 1 household-years in GRAIL villages, unlike the $72 \%$ in TRAIL villages. However, the loans increased the likelihood that a GRAIL borrower cultivated potatoes by $13 \%$ points (or 20\%, Column 1, $p<0.001$ ). Correspondingly, acreage (column 2) and output (column 3) increased significantly (23\% and $24 \%$, respectively). Revenue increased by $19 \%$ (column 5), but since the cost of production increased by a larger $28 \%$ (column 4 ), the GRAIL loans had a non-significant effect on value-added and imputed profit. ${ }^{26}$ The difference in the average treatment effects on imputed profits (column 7) across the two schemes is statistically significant at $10 \%$.

\footnotetext{
${ }^{23}$ We aggregate the data from the four-monthly surveys into a household-year level dataset capturing the amount of land households planted with potatoes, harvested quantities, sales, revenues, production costs, value-added and imputed profits. This allows us to align the costs of cultivation with the revenues, since harvested potatoes can be stored and then sold at different points in the year.

${ }^{24}$ Households reported to us the quantity and price of each potato sale. When they held potatoes for self-consumption, we imputed the sales revenue by pricing the potatoes at the median sale price in the village.

${ }^{25}$ To calculate the shadow cost of family labour, we price the reported family labor time (male, female and child labor separately) spent on the crop at the median wage reported for hired labor of that type in that village in that year for that crop.

${ }^{26}$ Since we analyse a large number of dependent variables, we correct for the increased chance of finding statistically significant results. Following Hochberg (1988), we report a conservative p-value for an index of variables in a family of outcomes taken together (see Kling et al. 2007). The variables are normalized by subtracting the mean in the control group and dividing by the standard deviation in the control group; the index is the simple average of the normalized variables. To adjust the p-value of the treatment effect for an index, the p-values for all indices are ranked in increasing order, and then each original p-value is multiplied by $m-k+1$, where $m$ is the number of indices and $k$ is the rank of the original p-value. If the resulting value is greater than 1 , we assign an adjusted p-value of $>0.999$.
} 
Thus, while both schemes led borrowers to plant more potatoes, only TRAIL borrowers earned larger profits as a result. This is mainly because they lowered their unit costs by $6 \%$, whereas GRAIL borrowers' unit costs increased by $2 \%$. The difference is statistically significant $(p<0.05) .{ }^{27}$

\section{Loan Performance}

In Table 6 we examine the take-up and repayment rates for the program loans. In column 1 , the dependent variable is the likelihood that a household eligible to take the loan in a given cycle actually took the loan. ${ }^{28}$ The sample means in Panel A show that eligible TRAIL Treatment households accepted $94 \%$ of the program loans offered, whereas eligible GRAIL Treatment households took $87 \%$ of the loan offers. The difference is statistically significant at the $1 \%$ level. This result holds $(p<0.01)$ even in Panel B when we control for household characteristics following the regression specification:

$$
y_{h v t}=\alpha_{0}+\alpha_{1} \mathrm{GRAIL}_{v}+\gamma \mathbf{X}_{i v t}+\varepsilon_{h v t}
$$

where $X_{i v t}$ includes the landholding, religion, caste, and the age and educational attainment of the oldest male member of the household, and a vector of loan cycle dummies to control for seasonal or other time-varying changes in take-up and repayment rates.

We define a loan to be in default if the repayment amount due was not paid fully by the due date. The average default rate over the three-year intervention period is an identically low $7 \%$ in both schemes (Table 6, Panel A, column 2). The regression result in Panel B confirms that there is no difference in the loan default rates in the two schemes. Despite the fact that the scheme did not increase their incomes significantly, GRAIL Treatment households repaid their loans at the same high rates as TRAIL Treatment households.

\section{Selection-based Explanation}

Next we examine the mechanisms that underlie our empirical findings. We start by examining how much of the difference in the average treatment effects in the two schemes

\footnotetext{
${ }^{27}$ TRAIL borrowers also faced a smaller decline in output price $(0.6 \%$ instead of $3.6 \%)$, but this difference is not statistically significant $(p=0.14)$.

${ }^{28}$ In loan cycles 2 and beyond, a Treatment household was only eligible to borrow if it had repaid at least $50 \%$ of the amount previously outstanding.
} 
can be explained by selection differences. This requires us to estimate a measure of the underlying heterogeneity among farmers, based on the following simple model. The key assumptions are that (a) farmers are heterogenous in ability, (b) more able farmers have higher TFP and lower unit costs of production, (c) the production function follows the Cobb-Douglas form and exhibits decreasing returns to scale, and (d) the informal credit market is efficient because lenders have perfect information about borrower ability and compete in Bertrand fashion. In particular, borrowers are not credit-rationed. The program loans provide them an extra line of credit at an interest rate below the prevailing market rate, and induce them to expand borrowing and cultivation scale.

\subsection{Estimation of Ability: Control Households}

Consider farmer $i$ in village $v$ in year $t$ who produces according to the function:

$$
Y_{i v t}=P_{v t} A_{i} \frac{1}{1-\alpha} l_{i v t}^{1-\alpha}
$$

$P_{v t}$ denotes a village-level yield or price shock, $l_{i v t}$ is the farmer's chosen scale of cultivation, and $\alpha \in(0,1)$. Farmer ability $A_{i}$ follows a common, given, distribution both in GRAIL and in TRAIL villages. The cost of production per unit area $c_{i}$ is constant for any given farmer, and decreases in farmer ability. Assume for now that $P_{v t}, A_{i}$ and $c_{i}$ are unaffected by the treatment. ${ }^{29}$

A farmer in village $v$, year $t$ who does not receive a program loan (henceforth, a control farmer) borrows from informal lenders. All informal lenders face the cost of capital $\rho_{v t} \cdot{ }^{30}$ Since these lenders compete in the Bertrand fashion, the farmer pays expected interest cost $\rho_{v t}$.

To cultivate potatoes, the farmer must incur a fixed cost $F>0$. Accordingly, the control farmer chooses $l=l_{i v t}^{c}$ to maximize

$$
P_{v t} A_{i} \frac{l^{1-\alpha}}{1-\alpha}-\rho_{v t} c_{i} l-F
$$

\footnotetext{
29 The current model assumes that farmer productivity and costs are correlated with a measure of exogenous ability. This is a special case of the model in our previous paper (Maitra et al. 2017). In Section 7 we allow the trader and agent to endogenously determine the extent to which they help and monitor the farmers, and these in turn affect the values of $A_{i}$ and $c_{i}$.

${ }^{30}$ In the presence of default risk, the informal interest rate also depends on, and is decreasing in, the farmer's ability, so that the expected interest cost of the borrower is $\rho_{v t}$.
} 
For control farmers with a sufficiently high ability, this yields

$$
\log l_{i v t}^{c}=\frac{1}{\alpha} \log \frac{A_{i}}{c_{i}}+\frac{1}{\alpha}\left[P_{v t}-\rho_{v t}\right]
$$

Observe that $\log \frac{A_{i}}{c_{i}}$, or the ratio of TFP to per-unit cost, is increasing in farmer ability. This serves as an exogenous measure of relative productivity. In equation 4 this ratio is scaled relative to $\alpha$; if $\alpha$ is close to 1 then it is also an absolute measure of the ratio of TFP to per-unit cost. Accordingly, among control farmers, productivity can be estimated as the household fixed effect in a household-year level panel regression, where the (log) scale of potato cultivation (acreage or output) is regressed on farmer, village and year dummies.

Equation (4) applies only to farmers with ability above the threshold $\underline{\theta}_{v t}$. These farmers eventually earn profits that cover the fixed cost $F$. Farmers with ability below this threshold would choose not to cultivate potatoes. Our data show that roughly 30 percent of Control 1 and Control 2 group farmers planted potatoes in at most one of the three years in our study period; we cannot estimate household fixed effects for these households. We call these households non-cultivators, and assign to them the lower endpoint of the estimated productivity distribution among the cultivators. This is an upper bound to their true latent productivity. None of the comparisons below are affected if we replace this upper bound with any lower estimate. Throughout we will use our estimate of productivity as a proxy for underlying unobserved ability.

In Table 7 we present the results from regressing each cultivator household's productivity estimate, obtained from the household fixed effects regression following equation (4), on household characteristics. ${ }^{31}$ As the bottom panel of Table 7 shows, there is wide variation in the estimated productivity level across households: the 75th percentile is more than three times the size of the 25th percentile. Although the productivity estimate correlates positively with landholding and having a male household head, the R-squared indicates that variation in observable characteristics can only explain $16 \%$ of the variation in household productivity. ${ }^{32}$ This justifies our working hypothesis that community-based agents have local information about farmers that an outsider would

\footnotetext{
${ }^{31}$ Table A2 presents the differences in demographic characteristics between the cultivators and noncultivators. Cultivators own more land, are more likely to be upper caste Hindus, have larger households, are more likely to be male-headed, and the oldest male in the household is likely to be older and is more likely to have completed primary school.

${ }^{32}$ A LASSO estimator performs only slightly better than the ordinary least squares estimator. Under the Extended Bayesian Information Criterion the selected LASSO model has an R-squared of 0.23.
} 
be unable to observe.

\subsection{Estimation of Ability: Treatment Households}

We cannot use the same procedure as in Section 6.1 to estimate the productivity of treated households, because the program loan would have a direct impact on treated households' scale of cultivation. Also, treated households could have engaged differently with their agent than control households. Instead, to recover their productivity estimate, we employ the Order-Preserving Assumption (OPA), which states that the treatment did not change households' rank order in terms of productivity levels. In Section 7.1 we will provide theoretical justification for this assumption. ${ }^{33}$ Under this assumption, in each treatment arm, we can rank Treatment farmers by cultivation scale, and assign to them the counterfactual productivity estimate $A_{i}$ of the farmer in the Control 1 distribution at the same rank, as estimated in Section 6.1. This gives us the correct estimate for the latent productivity of this farmer.

\subsection{Differences in Selection}

We can now examine whether the TRAIL and GRAIL agents systematically recommended households of different productivity levels. We focus on Control 1 and Control 2 households; neither group received program loans.

In Panel A of Figure 1, we compare the distributions of the productivity estimates for Control 1 and Control 2 households. ${ }^{34}$ The figure on the left shows that in TRAIL villages, the cumulative distribution function for Control 1 households first-order stochastically dominates that for the Control 2 households. A two-sample Kolmogorov-Smirnov test rejects the null hypothesis that the two distributions are identical $(p=0.005) .{ }^{35}$ Thus, the TRAIL agent positively selected borrowers on productivity. The figure on the right shows that the GRAIL agent also selected borrowers positively (K-S test $p=0.011) \cdot{ }^{36}$

\footnotetext{
${ }^{33}$ Athey and Imbens (2006) use a similar assumption in order to identify treatment effects in non-linear difference-of-difference settings.

${ }^{34}$ The flat segment in the bottom end of the plotted CDFs depicts the upper bound of the estimates for non-cultivators.

${ }^{35}$ Since our productivity estimates are generated variables, we also simulate 2000 bootstrap samples and run the Kolmogorov-Smirnov test for each Control 1 vs Control 2 CDF comparison. In 87 percent of the simulations, we can reject the null hypothesis that the two distributions are identical.

${ }^{36}$ The Kolmogorov-Smirnov test rejects the null hypothesis that the two distributions are identical in 83 percent of our bootstrap simulations.
} 
When in Panel B we again present the cumulative distribution functions for Control 1 households, we see that the graph for TRAIL households first-order stochastically dominates that for GRAIL households. A two-sample Kolmogorov-Smirnov test rejects the null hypothesis that the two distributions are identical $(p=0.06) .{ }^{37}$ Thus, the TRAIL agent selected more productive borrowers than the GRAIL agent.

For what follows, it is convenient to group sample households into productivity classes, or bins. Accordingly, we place all non-cultivator households in Bin 1. Among the rest, we use a median split to create Bins 2 and 3. Figure A2 shows that the GRAIL agent selected more Bin 1 borrowers (34.5\% versus 27.3\%), and fewer Bin 3 borrowers $(32.3 \%$ versus $39.7 \%) .{ }^{38}$

\subsection{Explaining Selection Differences}

What explains this difference in selection patterns? The TRAIL agent's experience lending and trading with village residents could have given him more or better information about their productivity levels. Alternatively, he might have had different incentives than the GRAIL agent. For example, the prospect of increasing his middleman profits might incentivize him to help farmers increase their crop volumes. Conversely, the GRAIL agent would likely share the motives of the political party controlling the village council. If this party pursues a pro-poor welfarist ideology, this might motivate the GRAIL agent to select asset-poor (and possibly) low-ability farmers. Alternatively, if the party is opportunistic and uses welfare programs clientelistically to mobilize votes, then too the GRAIL agent would recommend poor households for the loan scheme. ${ }^{39}$

We examine whether GRAIL agents used the loan recommendations for political gains. In our final survey round, we asked survey respondents to participate in a straw

\footnotetext{
${ }^{37}$ The Kolmogorov-Smirnov test rejects the null hypothesis that the two distributions are identical in 74 percent of our 2000 bootstrap simulations. Figure A1, in the Appendix, presents descriptive statistics on household productivity for TRAIL and GRAIL Control 1 households. TRAIL households had higher mean and maximum productivity estimates; the 25th, 50th and 75th percentiles or the distribution of productivity were also higher for TRAIL Control 1 households.

${ }^{38}$ The Bin 3 borrowers here could be thought of as equivalent to the gung-ho (GE) entrepreneurs in Banerjee et al. (2019). Indeed, the Bin 1 borrowers are akin to the non-GE entrepreneurs in that they do not cultivate potatoes absent the AIL loan. However, while Banerjee et al. (2019) argue that the overall differences in later outcomes between GE and non-GE entrepreneurs are driven by selection, we find in this paper that TRAIL and GRAIL borrowers have different outcomes conditional on selection, and that this difference is caused by differences in the agents' non-program incentives. See Section 6.5.

${ }^{39}$ It is a standard feature of the literature on political clientelism that political parties target swing voters among the poor. This is because poor voters sell their vote for a lower price (see, for example, Stokes 2005; Kitschelt and Wilkinson 2007).
} 
poll. Survey investigators gave them a sheet of paper resembling a ballot, and asked them to mark the symbol of their preferred political party, and then fold and place the paper in a box. ${ }^{40}$ If the straw poll vote indicates the political party that the respondent supports, then we can interpret a straw vote for the political party that was incumbent in 2010 as support for the political party of the GRAIL agent. We use data from the West Bengal State Election Commission to identify the incumbent political party in each local village council in 2010. We run the regression:

$$
I_{i v}=\xi_{0}+\xi_{1} \text { Treatment }_{i v}+\xi_{2} \text { Control } 1_{i v}+\gamma \mathbf{X}_{i v}+\varepsilon_{i v}
$$

where the dependent variable $I_{i v}$ takes the value 1 if the respondent $i$ in village $v$ voted for the incumbent party in the straw poll. The set of controls $\mathbf{X}_{i v}$ includes the same household characteristics included in equation (1). We run the regression separately for TRAIL and GRAIL villages. In Table 8 we see that the estimated treatment effect $\hat{\xi}_{1}-\hat{\xi}_{2}$ is positive and statistically significant in GRAIL villages (column 2), but insignificant in TRAIL villages (column 1).

Hence in GRAIL villages, those who were randomly selected to receive the program loan were $8 \%$ more likely to express support for the incumbent party than comparable households that were not offered the loan. Column 4 shows that the point estimate of the treatment effect is largest for the lowest-ability GRAIL households. This is consistent with opportunistic selection by the GRAIL agent, since clientelistic transfers are most likely to mobilize votes among the poor. It is also consistent with the incumbent following a pro-poor welfarist policy and thereby inducing greater gratitude among poor beneficiaries, that they express by voting for the party.

\subsection{The Role of Selection in Explaining ATE Differences}

We have seen that the TRAIL agent selected more productive borrowers than the GRAIL agent did. However it does not follow that this superior selection alone caused the larger impacts on borrower outcomes. In what follows, we examine how much of the differential impact of the TRAIL scheme on profits can be explained by differences in borrower productivity levels, and how much by differential effects conditional on productivity. Specifically, we will decompose the difference in the ATEs of the TRAIL and GRAIL schemes into the component attributable to differences in productivity, and

\footnotetext{
${ }^{40}$ Respondents were assured the response would be kept confidential and used only for research purposes. Less than $1 \%$ of households refused to participate.
} 
the component due to differences in conditional treatment effects.

In Table 9 we estimate bin-specific heterogenous treatment effects (HTEs) using the following specification:

$$
\begin{aligned}
y_{i v t} & =\sum_{k=1}^{3} \xi_{1 k} \widehat{\operatorname{Bin}}_{i k}+\sum_{i=1}^{3} \xi_{2 k}\left(\text { Control } 1_{i v} \times \widehat{\operatorname{Bin}}_{i k}\right)+\sum_{k=1}^{3} \xi_{3 k}\left(\text { Treatment }_{i v} \times \widehat{\operatorname{Bin}}_{i k}\right) \\
& +\sum_{k=1}^{3} \xi_{4 k} \widehat{\operatorname{Bin}}_{i k} \times \operatorname{GRAIL}_{v}+\sum_{k=1}^{3} \xi_{5 k}\left(\text { Control } 1_{i v} \times \widehat{\operatorname{Bin}}_{i k} \times \operatorname{GRAIL}_{v}\right) \\
& +\sum_{k=1}^{3} \xi_{6 k}\left(\text { Treatment }_{i v} \times \widehat{\operatorname{Bin}}_{i k} \times \operatorname{GRAIL}_{v}\right)+\gamma \mathbf{X}_{i v t}^{\prime}+\varepsilon_{i v t}
\end{aligned}
$$

Since household productivity is an estimated regressor, we bootstrap standard errors with 2000 iterations. ${ }^{41}$ In both schemes, the HTEs on value-added (column 7) are larger for borrowers of higher productivity, which indicates that a scheme that selects more able borrowers will likely generate a larger average treatment effect. Comparing the TRAIL and GRAIL HTEs for any given productivity bin, we also see that the point estimates are larger for the TRAIL scheme, although Panel $\mathrm{C}$ indicates that the differences are not statistically significant. ${ }^{42}$

Table 10 shows the results of the decomposition. The penultimate row indicates that holding everything else constant, if the TRAIL agents had followed the GRAIL agents' selection patterns, then the average treatment effect of the TRAIL scheme on potato value-added would have been $8.38 \%$ smaller than our actual estimate. The last row shows that if the GRAIL agents had kept their own selection pattern but their selected borrowers had had the same HTEs as the TRAIL borrowers in that productivity bin, then the gap in the ATEs would have narrowed by $75 \%$.

We infer that selection differences accounted for only a small fraction of the observed ATE difference. This conclusion is robust to using the continuous measure of productivity rather than the three discrete bins: with continuous productivity, selection

\footnotetext{
${ }^{41}$ For households that did not cultivate potatoes in any study year, we replace the value of potato area cultivated, output produced or profits earned with zero, thus we continue to include these households in the estimating sample. However the treatment effects on unit costs are only estimated in the subset of observations where potatoes were cultivated.

${ }^{42}$ Here we are abstracting from any heterogeneity of treatment effects within productivity bins. Our findings are similar when we consider continuous productivity levels instead. In Figure A3, the vertical difference in (smoothed) value-added between Treatment and Control 1 households gives us a visual estimate of the treatment effect at that productivity level. As the left panel shows, the vertical difference for TRAIL households is larger at larger productivity levels. The right panel shows that the GRAIL treatment effects are nearly always zero.
} 
differences explain $17.5 \%$ of the difference in ATEs, whereas differences in HTEs explain $82.5 \%$.

\subsection{Alternative Selection-based Explanation: Multidimensional Screening with Credit Rationing}

A potential concern with the selection model we described above is that in the presence of credit constraints, wealth levels affect credit access and thereby productivity (Galor and Zeira 1993; Banerjee and Newman 1993; Moll 2014; Kaboski and Townsend 2012; de Mel et al. 2008). If, in reality, borrowers differ both in ability and wealth, then even between two farmers of the same ability, the wealthier farmer would cultivate more. Further, if returns to scale are increasing, then the wealthier farmer would be more productive at the margin (Banerjee et al. 2019). Some part of the larger treatment effect of the TRAIL scheme could then be explained by the fact that the TRAIL agent selected wealthier farmers. If there are pecuniary scale economies, then these farmers' larger scale of cultivation could also explain their lower unit costs. In addition, farmers could differ in the extent to which this happens: lower-cost farmers could face larger reductions in unit cost as they expand their scale of cultivation. If cost and ability are not perfectly correlated, then our sole focus on ability differences might incorrectly attribute too little of the ATE of the TRAIL scheme to selection.

In Section A1 in the Appendix, we present a model where farmers differ on three dimensions: ability, wealth and cost. Assuming constant elasticity forms of the production function and the unit cost function, and assuming also that all farmers are credit rationed, we can use panel data on farmers' unit costs and revenue to back out these elasticities and the three dimensional "type" of each control farmer. Specifically, the production function is

$$
\log y_{i v t}=\log a_{i}+\mu \log l_{i v t}+\delta_{2 v t}
$$

where $a_{i}$ denotes ability, $l_{i v t}$ denotes area cultivated, $y_{i v t}$ denotes revenue, $\delta_{2 v t}$ denotes a village-year productivity shock and $\mu$ represents returns to scale. The cost function is

$$
\log u_{i v t}=\log c_{i}+\zeta \log l_{i v t}+\log q_{v t}
$$

where $u_{i v t}$ denotes cost per acre, $c_{i}$ denotes the farmer's cost type, and $q_{v t}$ denotes a village-year cost shock, and $\zeta$ represents elasticity of unit cost with respect to the scale of cultivation, representing pecuniary scale effects. The credit-rationed farmer's total 
cultivation cost $\left(C_{i v t}\right)$ is determined by his financial access according to the equation:

$$
\log C_{i v t}=\log w_{i}+\log \gamma_{v t}
$$

where $w_{i}$ represents a measure of the farmer's wealth, and $\gamma_{v t}$ is a village-year shock to the supply of credit. The three dimensions of type: ability, cost and wealth can be estimated as farmer fixed effects in the panel regressions corresponding to these three equations. As shown in the Appendix, the model predicts that the treatment effect of expanding credit access by one percent equals the "quasi-profit" $\pi_{i v t}^{Q} \equiv\left[\frac{\mu}{1+\nu} R_{i v t}-C_{i v t}\right]$ of Control 1 household $i$ in village $v$ in year $t$, where $R_{i v t}$ denotes the revenue earned by farmer $i$ in village $v$ in year $t$, and $C_{i v t}$ is the cultivation cost, as defined above. Taking expectations of this with respect to unit mean village-year shocks, the predicted treatment effect for a farmer is a function of the three dimensions of the farmer's type, according to the expression:

$$
\pi_{i}^{Q}=a_{i}\left[\frac{w_{i}}{c_{i}}\right]^{\frac{\mu}{1+\zeta}}-\frac{w_{i}}{\left(c_{i}\right)^{\frac{1}{1+\zeta}}}
$$

We refer to the quasi-profit as the "reduced form estimate" of the treatment effect, and to the expression in equation (10) above as the "structural estimate".

To examine if this model can explain our empirical results, we follow equations (7), (8) and (9) and estimate the three dimensions for each control household in the TRAIL and GRAIL villages. The cumulative distribution functions for each of the three types are presented in Figure A4. We see in Panel B that control farmers in TRAIL and GRAIL villages have almost identical ability distributions. In Panel A the cumulative distribution functions for cost type cross, although a larger fraction of TRAIL farmers have low unit costs over a wide range. Similarly, the CDFs for wealth cross, although a larger fraction of TRAIL farmers have high wealth over a wide range.

The corresponding estimates of $\zeta$ and $\mu$ are presented in Table 11. Row 4 displays "reduced form" estimates of average quasi-profit in the two schemes, using observed revenues and costs of Control 1 subjects, adjusted using the estimated elasticities. This is multiplied by the proportional change $(\Delta)$ in the scale of cultivation (Row 2) to generate a "reduced form" estimate of the ATEs predicted, in Row 5. The corresponding "structural estimates" of selected farmers' quasi-profit based on their estimated types is shown in Row 6, and the corresponding predicted percentage effect on potato valueadded in Row 7. 
We see that the model's reduced form estimate of the TRAIL ATE (Rs. 2732) is very similar to our actual empirical estimate (Rs. 2059, see Table 5 column 7 ). However for the GRAIL ATE the model produces a vast overestimate (Rs. 3481 v. Rs. 492). Similarly, the structural estimate of the TRAIL scheme's effect on value-added (36.48\%) is similar to the $35.92 \%$ that we obtained in Table 5 , but the estimate for the GRAIL scheme's effect $(33.48 \%)$ is nearly four times as large as the estimated GRAIL ATE $(8.45 \%)$.

Rows 8 through 12 show how the predicted ATEs are modified when we replace the estimated returns to scale elasticity $(\mu)$ with an IV estimate. ${ }^{43}$ The predicted percentage effects on potato value-added are not significantly altered, so the predicted GRAIL ATE continues to be larger than the predicted TRAIL ATE. Hence allowing for credit rationing and extending the dimensions of heterogeneity to include wealth and unit cost does not help explain our empirical result that the TRAIL scheme generated a larger ATE than the GRAIL scheme.

Below we present an alternative model that instead emphasizes differences in the TRAIL and GRAIL outcomes conditional on borrower selection.

\section{$7 \quad$ A Model Of Agent-Farmer Interactions}

In this model, TRAIL and GRAIL agents interact with program borrowers so as to influence their cultivation, purchase and sales choices and crop outcomes. Interactions take the form of conversations about the weather, market prices, cultivation techniques and harvesting times. Through these conversations agents might monitor farmers' actions, and provide technical advice and marketing assistance.

Agents are motivated to engage with farmers because of their program as well as non-program incentives. Since the TRAIL agent is also a trader, he has a stake in both the upside and downside of the farmer's cultivation project. Not only does an abundant harvest ensure that he receives his TRAIL commission, it also earns him a larger middleman profit. On the downside, a failed crop wipes out both his commission and his profit. The GRAIL agent is a political appointee and so has incentives aligned with his village council. The elected village leaders may benefit if the scheme is perceived to be a success, and so the GRAIL agent may want to ensure that poor borrowers repay

\footnotetext{
${ }^{43}$ This elasticity estimate is discussed in more detail in Section 7. It is obtained from a regression (equation (14) below) of log output per acre on log area cultivated and village year dummies using Treatment and Control households, with treatment dummies as an instrument for area cultivated.
} 
their loans. This gives him a stake in the success of the crop, but conditional on crop success, he has no additional benefit from a large harvest.

In turn these different motivations will shape the specific manner in which the agents engage with the farmer: either helping to increase the harvest size, or monitoring to reduce default risk.

\subsection{Assumptions and Predictions}

Farmers vary in intrinsic ability, denoted by the single dimension $\theta$. Their crop is successful with probability $p(\theta, m)$ where $p_{\theta}>0, p_{m}>0, p_{m m}<0, p_{\theta m}<0$ : lower ability farmers are riskier, and monitoring $(m)$ reduces their risk by more. In the event of success, output is $a(\theta, m) f(l)$, where $a_{\theta}>0, a_{m}<0, f_{l}>0, f_{l l}<0,-\frac{f^{\prime \prime}}{f^{\prime}}$ is non-increasing, and $p$ varies relatively little with $\theta \cdot{ }^{44}$ Expected TFP $A(\theta, m) \equiv a(\theta, m) p(\theta, m)$ satisfies $A_{m}<0$. The farmer's cultivation cost is $c(h, m) l$, where $l$ is area cultivated, $h$ is the level of help he receives, and $c_{h}<0, c_{h h}>0, c_{m}>0$. We also assume $c_{h m}=0$; this simplifies the analysis but is not critical. Whereas monitoring increases unit costs and lowers risk and expected productivity, help has no effect on risk and lowers unit cost. For instance, monitoring induces the farmer to act to lower the chance of crop failure, such as by spending more on pesticides. These activities are expensive and time consuming, and so the farmer's unit cost rises and productivity fall. On the other hand, the agent can help the farmer lower costs or raise quality of inputs, by providing valuable business advice about the brands to purchase and where to purchase them. We also assume that the relevant functions are smooth with well-behaved curvature, so that optimal allocations are interior, satisfying suitable first and second order conditions.

Traders and farmers enter into bilateral interlinked credit-cum-output contracts, where the trader provides the farmer credit for working capital, help and monitoring, and the farmer cultivates the specified area, and then sells his harvest to the trader. Both parties are risk-neutral. Farmers have zero wealth, and traders have unlimited access to credit at a constant cost $\rho$. The contracts are the outcome of an efficient equilibrium in a frictionless contract market where traders know farmers' ability. Traders incur interaction costs of $\gamma_{T}(h+m)$ and credit costs of $\rho$ per rupee loaned, and earn per unit return of $\tau$ when they sell the farmer's crop on an external market. The farmer cannot repay the loan if the crop fails, but otherwise repays at interest rate $r$, and receives a

\footnotetext{
${ }^{44}$ This is in comparison to how much TFP $a$ varies with $\theta$. This assumption ensures that treatment effects of the TRAIL scheme increase in $\theta$. See Maitra et al. (2017) for further details.
} 
lumpsum side payment $s$ from the trader when the contract is signed. Hence a control farmer of type $\theta$ enters into a contract specifying $\left(l^{c}(\theta), m^{c}(\theta), h^{c}(\theta), r^{c}(\theta), s^{c}(\theta)\right)$, where $(l, m, h)=\left(l^{c}(\theta), m^{c}(\theta), h^{c}(\theta)\right)$ maximizes joint expected payoffs of the farmer-trader pair:

$$
(1+\tau) A(\theta, m) f(l)-(1+\rho) c(h, m) l-\gamma_{T}[m+h]
$$

The interest rate $r^{c}(\theta)$ is then set to "decentralize" the efficient scale decision $l^{c}(\theta)$ to the farmer, so that the farmer selects the efficient area $l^{c}(\theta)$ in his own self-interest: $l=l^{c}(\theta)$ maximizes $A\left(\theta, m^{c}(\theta)\right) f(l)-p\left(\theta, m^{c(\theta)}\left(1+r^{c}(\theta)\right) c^{c(\theta)}(h, m) l .{ }^{45}\right.$ The side-payment depends on the relative bargaining power of the trader and the farmer. The details of the model are presented in Section A2 in the Appendix.

In an optimal contract, traders do not monitor control farmers $\left(m^{c}(\theta) \equiv 0\right)$, but they do help them $\left(h^{c}(\theta)>0\right)$. Monitoring is inefficient because it lowers expected productivity and is costly for both farmer and trader, and produces no benefits since neither party is risk-averse. Help is efficient because it raises expected productivity, and so it is provided as long as $\gamma_{T}$ is not too large. The help induces the farmer to plant more area $(l)$, and earn greater profit per acre. More able farmers receive more help, because per unit of trader's time, help generates a greater expected return when the farmer has higher ability. Hence we obtain the following testable predictions for control farmers:

(i) Higher ability farmers are less likely to default, and pay a lower interest rate;

(ii) Higher ability farmers produce more output, and incur lower unit costs.

In TRAIL villages, a trader is selected as the agent. Suppose a farmer of type $\theta$ is offered the TRAIL loan. This allows him to supplement his informal loan from the trader at interest rate $r_{T}<\rho$, and thus expand acreage by $l^{t}$. We assume he cannot reduce the area that was already agreed upon before the scheme was introduced, while trader help and monitoring decisions can be freely modified. The farmer repays the TRAIL loan only if his crop succeeds. The TRAIL agent receives a commission $\psi<1$ per rupee interest repaid. The trader-farmer pair then modify their contract decisions by choosing $\left(l^{t}, m^{t}, h^{t}\right)=\left(l^{t}(\theta), m^{t}(\theta), h^{t}(\theta)\right)$ to maximize

$$
(1+\tau) A(\theta, m) f\left(l^{c}(\theta)+l^{t}\right)-\left[(1+\rho) l^{c}(\theta)+\left\{1+r_{T}(1-\psi)\right\} p(\theta, m) l^{t}\right] c\left(h^{t}, m^{t}\right)-\gamma_{T}\left(h^{t}+m^{t}\right)
$$

\footnotetext{
${ }^{45}$ Note that $1+r^{c}(\theta)=\frac{1+\rho}{(1+\tau) p(\theta, 0)}$, so $r^{c}(\theta)$ decreases in $\theta$.
} 
Let the resulting outcomes for TRAIL treated farmer of type $\theta$ be denoted $l^{T}(\theta) \equiv$ $l^{c}(\theta)+l^{t}(\theta), m^{T}(\theta)=m^{t}(\theta), h^{T}(\theta)=h^{t}(\theta)$. The variables $l^{T}(\theta)$ and $h^{T}(\theta)$ are increasing in $\theta$, while $m^{T}(\theta) \equiv 0$. Hence the Order-Preserving Assumption (OPA) holds. The model then predicts:

(iii) Among treated farmers in the TRAIL scheme, those with higher ability produce more and receive more help, and incur lower unit costs;

(iv) In the TRAIL scheme, a treated farmer produces more, earns more profit and incurs lower unit costs than a control farmer of the same ability level.

In the GRAIL scheme, a third party who is not a trader is appointed as the agent. The GRAIL agent earns expected payoff $v(\theta) p(\theta, m)-\gamma_{G} m$ where $v(\theta)$ represents a welfare weight on the farmer, weighted by the default rate, and $m$ is the extent to which the agent monitors the farmer. The welfare weight is decreasing in $\theta$, reflecting the pro-poor ideological or opportunistic objectives of the political party the GRAIL agent represents. These objectives are achieved as long as the farmer does not default on the GRAIL loan. ${ }^{46}$ The commission enters into the welfare weight. This may bias the GRAIL agent in favor of high ability farmers, because they borrow more, cultivate larger areas and produce more. We assume that this consideration for personal financial gain is outweighed by the political considerations which create a bias in the opposite direction. Not being a trader, the GRAIL agent is not in a position to provide business advice and help to the farmer, but can monitor him. The cost of monitoring of the GRAIL agent is $\gamma_{G}$.

Given a farmer of type $\theta$ selected for a GRAIL loan, the GRAIL agent's monitoring level $m^{G}(\theta)$ will maximize $v(\theta) p(\theta, m)-\gamma_{G} m$. Given this monitoring level, the farmer renegotiates his contract with his trade partner. It is easy to check the trader will continue to have no incentive to monitor the farmer. Hence, given $m^{G}(\theta)$, the revised contract will select supplementary area cultivated $l^{g}=l^{g}(\theta)$ and revised help $h^{g}=h^{g}(\theta)$ to maximize their joint payoff

$$
(1+\tau) A\left(\theta, m^{G}(\theta)\right) f\left(l^{c}(\theta)+l^{g}\right)-\left[(1+\rho) l^{c}(\theta)+p(\theta, m)\left(1+r_{T}\right)\right] c\left(h^{g}, m^{g}\right) l^{g}-\gamma_{G} h
$$

Let the resulting GRAIL treated outcomes be denoted $\left(l^{G}(\theta) \equiv l^{c}(\theta)+l^{g}(\theta), m^{G}(\theta), h^{G}(\theta)\right)$. $m^{G}(\theta) \geq 0=m^{T}(\theta)$ and $m^{G}(\theta)$ is decreasing. We find that the Order Preserving As-

\footnotetext{
${ }^{46}$ Here we simplify by assuming that the farmer's profits do not enter the GRAIL agent's objective. More substantively, the GRAIL agent worries about only the downside risk faced by the farmers they select, but does not obtain any benefit if the farmer avoids a default and earns a large profit.
} 
sumption holds in the GRAIL scheme. We obtain the following predictions for GRAIL treated farmers:

(v) The GRAIL agent interacts more with low ability agents. GRAIL borrowers are less likely to default on their loans than TRAIL borrowers of the same ability level.

(vi) If the production function has constant elasticity, a GRAIL treated farmer cultivates a smaller area, receives less help, achieves a smaller reduction in unit costs, and a smaller increase in expected profits, than a TRAIL treated farmer of the same ability.

This model thus explains larger heterogenous treatment effects for the TRAIL scheme, which can account for a larger TRAIL ATE even in the absence of any selection differences. This is mainly because TRAIL treated farmers receive more help. In turn, this is due to the different non-program objectives of the TRAIL and GRAIL agents. TRAIL agents farmers want the borrowers to produce more, so that they can earn larger middleman profits. The help is more effective at raising crop output if the farmer is more able. On the other hand, the GRAIL agent monitors treated farmers so as to reduce default risk. This raises their unit cost and lowers their productivity, and so GRAIL treated farmers produce less and earn smaller profits than TRAIL treated farmers. These effects are larger, the less able the farmer. Observe finally that the model also explains the different selection incentives of the two agent types: the TRAIL agent benefits more from more able farmers, while the GRAIL agent benefits more from less able farmers.

\subsection{Testing Predictions of the Model}

Before testing the predictions, we test the underlying assumption of decreasing returns to scale. We regress per acre productivity as a double-log-linear function of log area cultivated, farmer fixed effects and village-year shocks

$$
\log \left[\frac{R_{i v t}}{l_{i v t}}\right]=\log a_{i}+(\mu-1) \log l_{i v t}+\log q_{v t}+e_{i v t}
$$

The elasticity $(\mu-1)$ with respect to area cultivated can be estimated by instrumental variables on the sample of Treatment and Control 1 farmers, with the treatment dummy as the instrument. We have already seen that treatment has a significant positive effect on area cultivated, while the randomization ensures that the exclusion restriction is satisfied. We obtain an IV estimate of $(\mu-1)=-.094$, which is statistically insignificant 
( $\mathrm{p}$-value of the one-sided test of the null hypothesis $(\mu-1)=0$ is 0.81$)$. Hence we have weak evidence for decreasing returns to scale.

To test prediction $(i)$ about the variation of control farmers' interest rates with ability, Column 1 of Table 12 presents the OLS regression results of interest rates paid on informal loans by Control 1 households, using the pooled sample of TRAIL and GRAIL households. We restrict our sample to informal loans taken before our intervention began, to avoid potential contamination from the intervention on borrowers' interest rates. ${ }^{47}$ The coefficient estimate of productivity is negative $(p=0.11)$ indicating that for control households, there is a decline in interest rate as productivity increases. The average control household in Bin 1 reported taking loans at $21 \%$ interest per annum. This is significantly higher than the $15 \%$ that Bin $2(p=0.03)$ and the $16 \%$ that Bin 3 households reported $(p=0.04) .{ }^{48}$ Hence the evidence confirms prediction $(i)$.

Next consider prediction (ii) about how output and unit cost vary with ability among control farmers. Columns 2 and 3 of Table 12 present OLS regression results of potato ouput (in kg) and input cost per acre in potato cultivation (in Rs.) on the productivity estimate. The regressions control for year dummies, and pertain to all Control 1 and Control 2 households. Consistent with prediction (ii), column 2 shows that output is increasing in productivity, while column 3 shows that unit costs are decreasing in productivity.

Now turn to prediction $(\mathrm{iii})$ for TRAIL treated farmers. At each four-monthly survey interview, we asked sample households whether in the previous three days they had spoken with the local trader or the agent (separately) about cultivation, the harvest, or output sales. Since in the TRAIL scheme the agent is also a trader, we include interaction with the trader as well as the agent (in case the agent is a different trader) to measure number of interactions with traders. ${ }^{49}$ In column 4 of Table 12 we see that TRAIL Treatment households' interacted more with the agent if they had higher ability. Columns 5 and 6 of Table 12 present the OLS regressions of quantity of potato cultivated and input cost per acre in potato cultivation on productivity for TRAIL Treatment

\footnotetext{
${ }^{47}$ Since only 10 households in each village received the program loans, we do not believe there were any spillover or general equilibrium effects.

${ }^{48}$ These averages are presented in the left panel of Figure A6. The right panel of this Figure uses continuous variation in productivity. Recall that we do not have a continuous measure of productivity for those who did not cultivate potatoes; for this group we compute the mean informal interest rate and plot it as a single point in the right panel of Figure A6. For Bins 2 and 3, we run a locally-weighted polynomial regression of the mean interest rate on farmer productivity.

${ }^{49}$ Since the GRAIL agent is not a trader, when we measure the number of interactions with the GRAIL agent we will not include interactions with the trader.
} 
households. Consistent with prediction (iii), more productive TRAIL Treatment farmers interacted more with the agent, and produced more potatoes, at a lower input cost per acre.

Table 9 provides evidence about prediction $(i v)$. The TRAIL HTEs on potato acreage, potato output and input cost per acre in potato cultivation (see columns 2, 3 and 10 respectively) conform to prediction ( $i v)$, and most are statistically significant.

Finally, we test the predictions about the GRAIL scheme, and its comparison with the TRAIL scheme. Start with prediction $(v)$. Column 11 of Table 9 presents the HTEs on agent interactions in TRAIL and GRAIL. As the results in Panel B show, they are decreasing in ability in the GRAIL scheme indicating that the GRAIL agent interacts more with low ability farmers. On the other hand they are increasing in ability in the TRAIL scheme, indicating that the TRAIL agent increases his interaction with higher-ability farmers more.

Figure 2 presents the default rates on program loans by TRAIL and GRAIL treated households by productivity bin. TRAIL Treatment households in productivity Bin 1 defaulted on 9.3 percent of their loans, whereas GRAIL Bin 1 Treatment households defaulted at a significantly lower 5 percent $(p=0.03)$. In Bins 2 and 3 the differences in default rates across TRAIL and GRAIL go the other way, although they are not statistically significant. This is consistent with prediction $(v)$.

To check prediction $(v i)$, consider the results presented in Panel $\mathrm{C}$ of Table 9. For every productivity bin, TRAIL treatment effects on acreage, output and value-added exceed the corresponding GRAIL treatment effects (although the differences are not statistically significant): see columns 2,3 and 7 . For every productivity bin, the TRAIL treatment effects on unit costs are lower than the corresponding GRAIL treatment effects and the difference is statistically significant for Bin 3. See column 11. This is consistent with prediction $(v i)$.

\section{Concluding Comments}

This paper finds evidence that appointing private traders as intermediaries to deliver credit, as in the TRAIL scheme, resulted in significant impacts on borrower production and farm incomes. When the local elected council appointed the intermediary, as in the GRAIL scheme, this did not have a significant impact on borrower incomes, though it did increase production. The difference was due to the different impacts on cultivation costs: TRAIL treated households reduced their unit costs of production while the 
GRAIL treated households did not. Further, although the TRAIL agent selected more productive farmers to participate in the scheme than the GRAIL agent did, this could only explain very little of the difference in outcomes. Instead, the TRAIL agents' interaction with treated farmers were far more important: they increased their interactions with treated farmers, and to a greater extent with more productive farmers. GRAIL agents also interacted more with treated farmers, but to a greater extent with less productive farmers; this appears to have caused them to default less than their TRAIL counterparts. The results are consistent with a model of endogenous agent-farmer interactions where the TRAIL agent helped treated farmers reduce production costs by providing helpful advice, while the GRAIL agent monitored treated farmers more intensively, thus reducing their default rates and raising production costs. In this model, the GRAIL agent resembles a private holder of debt, motivated primarily to reduce borrower default risk, while the TRAIL agent is like an equity holder who shares risk evenly with the farmer and is motivated to provide useful information and advice. Although the TRAIL agent did not monitor the treated farmers, TRAIL and GRAIL loans still had similar repayment rates, because the TRAIL borrowers were more able farmers to start with, and so were less likely to default. The GRAIL agent selected a larger proportion of low ability farmers with higher ex ante risk, and then monitored them intensively to lower these risks.

The more general lesson is that the role of the intermediary was not confined to selecting beneficiaries and achieving better targeting. The differences in the nature of network connections with the intermediary mattered significantly for the eventual success of the program. In particular the endogenous change in this relationship resulting from the intervention accounts for most of the differences in impacts on beneficiary incomes. Policy interventions that employ local intermediaries could benefit from considering this mechanism at the time of intervention design.

\section{References}

Alatas, V., A. Banerjee, R. Hanna, B. A. Olken, R. Purnamasari, and M. Wai-Poi (2016). Self-targeting: Evidence from a field experiment in indonesia. Journal of Political Economy 124(2), 371 - 426.

Alatas, V., A. Banerjee, R. Hanna, B. A. Olken, and J. Tobias (2012). Targeting the poor: Evidence from a field experiment in indonesia. American Economic Review 102(4), 1206 - 1240.

Athey, S. and G. W. Imbens (2006). Identification and inference in nonlinear difference-in-differences models. Econometrica $74(2), 431-497$. 
Atkinson, A. B. (1970). On the measurement of inequality. Journal of Economic Theory 2, $244-263$.

Bandiera, O. and I. Rasul (2006). Social networks and technology adoption in northern mozambique. Economic Journal 116(514), 869 - 902.

Banerjee, A., E. Breza, E. Duflo, and C. Kinnan (2019). Can microfinance unlock a poverty trap for some entrepreneurs. Technical report, NBER Working Paper.

Banerjee, A., A. G. Chandrasekhar, E. Duflo, and M. Jackson (2013). The diffusion of microfinance. Science 341, $363-372$.

Banerjee, A. V. and A. F. Newman (1993). Occupational choice and the process of development. Journal of Political Economy 101, $274-298$.

Bardhan, P., S. Mitra, D. Mookherjee, and A. Nath (2015). Resource transfers to local governments: Political manipulation and voting patterns in west bengal. Technical report, IED Working Paper, Boston University.

Bardhan, P. and D. Mookherjee (2016). Clientelistic politics and economic development: An overview. Technical report, IED Working Paper, Boston University.

Beaman, L., A. BenYishay, J. Magruder, and M. Mobarak (2018). Can network theory-based targeting increase technology adoption? Technical report, NBER Working Paper 24912.

Beaman, L. and J. Magruder (2012). Who gets the job referral? evidence from a social networks experiment. American Economic Review 102(7), $3574-3593$.

Berg, E., M. Ghatak, R. Manjula, D. Rajasekhar, and S. Roy (2018). Motivating knowledge agents: Can incentive pay overcome social distance? Economic Journal 129(617), 110 - 142.

Casey, K. (2018). Radical decentralization: Does community-driven development work? Annual Review of Economics 10, 138 - 163.

Chandrasekhar, A. G., A. Banerjee, E. Duflo, and M. Jackson (2018). Using gossips to spread information: theory and evidence from two randomized controlled trials. Review of Economic Studies Forthcoming.

de Mel, S., D. McKenzie, and C. Woodruff (2008). Returns to capital in microenterprises: Evidence from a field experiment. Quarterly Journal of Economics 123(4), 1329 - 1372.

Debnath, S. and T. Jain (2018). Social connections and public healthcare utilization. Technical report, Mimeo, Indian School of Business.

Deserranno, E., M. Stryjan, and M. Sulaiman (2018). Leader selection and service delivery in community groups: Experimental evidence from uganda. Technical report, Northwestern University.

Devarajan, S. and S. Khemani (2016). If politics is the problem, how can development assistance be part of the solution? Technical report, World Bank.

Dey, S. and K. Sen (2016). Is partisan alignment electorally rewarding? evidence from village council elections in india. Technical report, University of Manchester Working Paper.

Fisman, R., D. Paravisini, and V. Vig (2017). Social proximity and loan outcomes: Evidence from an indian bank. American Economic Review 107(2), 457 - 492. 
Fuentes, G. (1996). The use of village agents in rural credit delivery. Journal of Development Studies 33(2), $188-209$.

Galor, O. and J. Zeira (1993). Income distribution and macroeconomics. The Review of Economic Studies 60(1), $35-52$.

Heath, R. (2018). Why do firms hire using referrals? evidence from bangladeshi garment factories. Journal of Political Economy 126(4), 1691 - 1746.

Hochberg, Y. (1988). A sharper bonferroni procedure for multiple tests of significance. Biometrika 75 (4), $800-802$.

Hussam, R., N. Rigol, and B. Roth (2018). Targeting high ability entrepreneurs using community information: Mechanism design in the field. Mimeo, Harvard Business School.

Kaboski, J. P. and R. M. Townsend (2012). The impact of credit on village economies. American Economic Review 4(2), 98 - 133

Kitschelt, H. and S. Wilkinson (2007). Patrons, Clients and Policies: Patterns of Democratic Accountability and Political Competition. Cambridge University Press: Cambridge and New York.

Kling, J. R., J. B. Liebman, and L. F. Katz (2007). Experimental analysis of neighborhood effects. Econometrica 75, $83-119$.

Maitra, P., S. Mitra, D. Mookherjee, A. Motta, and S. Visaria (2017). Financing smallholder agriculture: An experiment with agent-intermediated microloans in india. Journal of Development Economics $127,306-337$.

Maitra, P., S. Mitra, D. Mookherjee, and S. Visaria (2019). Evaluating the distributive effects of a development intervention. Technical report, Hong Kong University of Science and Technology.

Mansuri, G. (2007). Credit layering in informal financial markets. Journal of Development Economics $84(2), 715-730$.

Mansuri, G. and V. Rao (2013). Localizing development: Does participation work? Technical report, Washington, DC: World Bank.

Mitra, S., D. Mookherjee, M. Torero, and S. Visaria (2018). Asymmetric information and middleman margins: An experiment with west bengal potato farmers. Review of Economics and Statistics $C(1)$, $1-13$.

Moll, B. (2014). Productivity losses from financial frictions: Can self-financing undo capital misallocation? American Economic Review 104(10), 3186 - 3221.

Robinson, J. and T. Verdier (2013). The political economy of clientelism. Scandivanian Journal of Economics 115(2), $260-291$.

Stokes, S. (2005). Perverse accountability: A formal model of machine politics with evidence from argentina. Americal Political Science Review 99(3), 315 - 325.

Varghese, A. (2005). Bank-moneylender linkage as an alternative to bank competition in rural credit markets. Oxford Economic Papers 57(2), 315 - 355.

Vera-Cossio, D. A. (2018). Targeting credit through community members. Technical report, University of California, San Diego.

World Development Report (2004). Making Services Work for Poor People. World Bank, Washington D. C. 


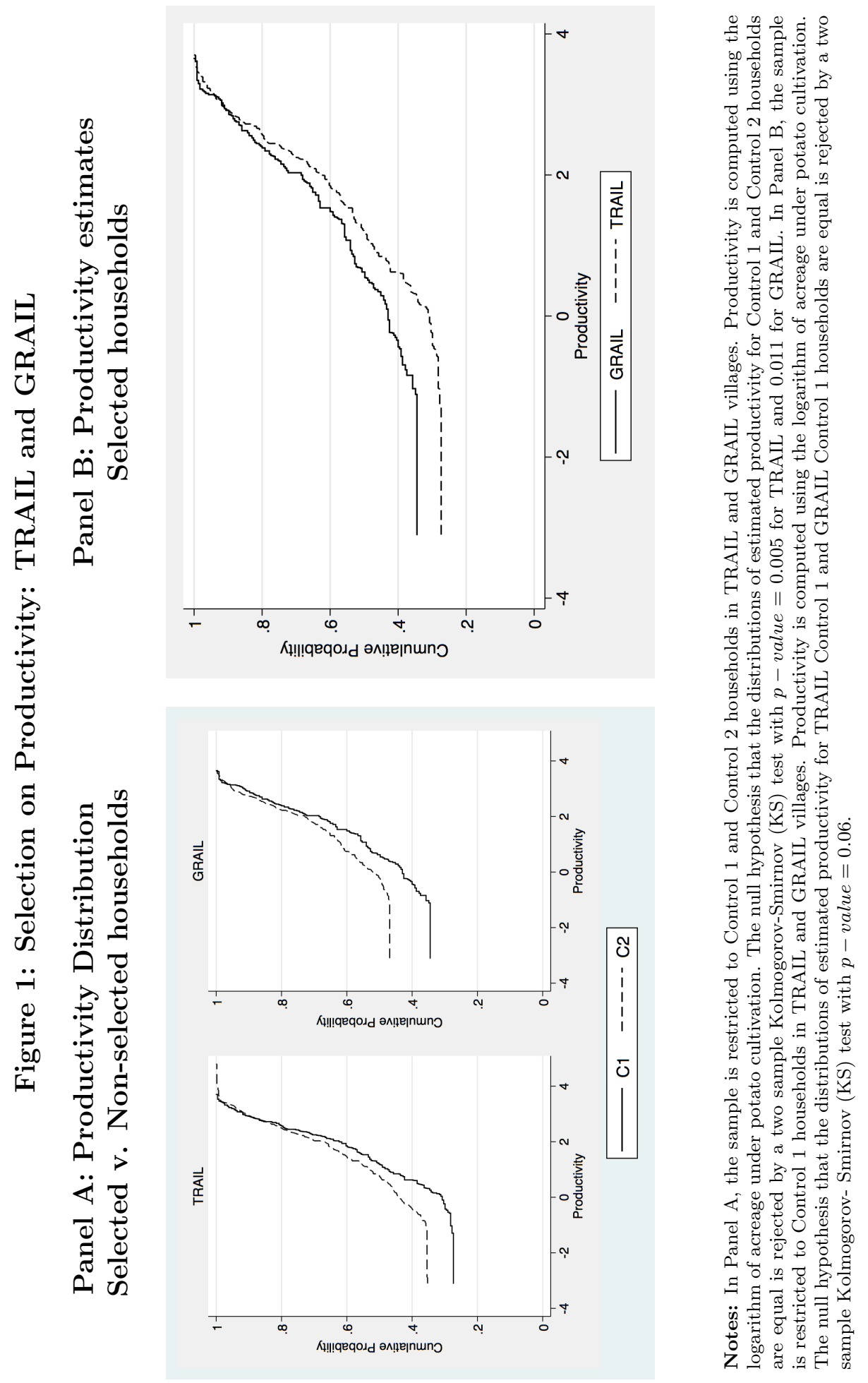


Figure 2: Default Rates on TRAIL and GRAIL Loans, by Productivity Bin

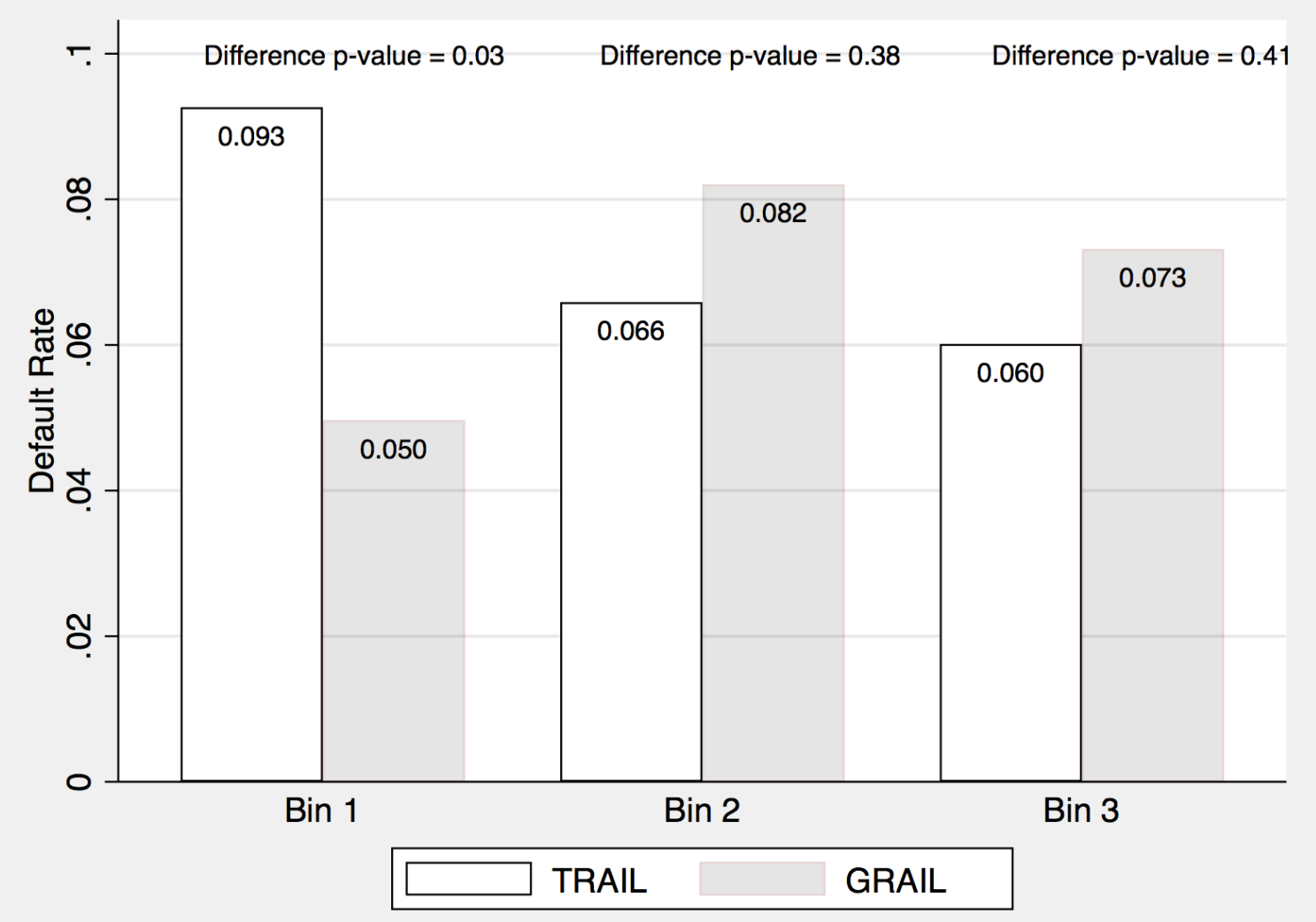

Notes: The height of each bar measures the fraction of program loans that were not repaid fully by the due date. The sample is restricted to Treatment households in TRAIL and GRAIL villages with at most 1.5 acres of land. p-value of difference between default rate between TRAIL and GRAIL for each Bin presented. Productivity is computed using the logarithm of the acreage under potato cultivation. 
Table 1: Randomization

\begin{tabular}{|c|c|c|c|}
\hline & $\begin{array}{l}\text { TRAIL } \\
\quad(1)\end{array}$ & $\begin{array}{l}\text { GRAIL } \\
\quad(2)\end{array}$ & TRAIL $\underset{(3)}{- \text { GRAIL }}$ \\
\hline \multicolumn{4}{|l|}{ Panel A: Village level characteristics } \\
\hline Number of Households & $\begin{array}{c}276.04 \\
(201.59)\end{array}$ & $\begin{array}{c}252.21 \\
(238.36)\end{array}$ & 23.83 \\
\hline Number of Potato Cultivators & $\begin{array}{c}164.63 \\
(130.30)\end{array}$ & $\begin{array}{c}160.75 \\
(168.39)\end{array}$ & 3.88 \\
\hline \multicolumn{4}{|l|}{ Of which: } \\
\hline & $\begin{array}{l}15.96 \\
(18.98)\end{array}$ & $\begin{array}{l}27.96 \\
(75.63)\end{array}$ & -12.00 \\
\hline Own $0-1.25$ acres & $\begin{array}{c}113.88 \\
(103.22)\end{array}$ & $\begin{array}{c}99.67 \\
(78.00)\end{array}$ & 14.21 \\
\hline Own $1.25-2.50$ acres & $\begin{array}{c}25.58 \\
(16.27)\end{array}$ & $\begin{array}{l}24.63 \\
(25.20)\end{array}$ & 0.96 \\
\hline Own $2.50-5.00$ acres & $\begin{array}{l}10.88 \\
(7.39)\end{array}$ & $\begin{array}{l}12.83 \\
(17.11)\end{array}$ & -1.96 \\
\hline Own $5.00-12.50$ acres & $\begin{array}{l}1.38 \\
(1.79)\end{array}$ & $\begin{array}{c}1.17 \\
(1.95)\end{array}$ & 0.21 \\
\hline Own more than 12.50 acres & $\begin{array}{c}0.00 \\
(0.00)\end{array}$ & $\begin{array}{c}0.04 \\
(0.20)\end{array}$ & -0.04 \\
\hline \multicolumn{4}{|l|}{ Panel B: Household level characteristics } \\
\hline Head: More than Primary School & $\begin{array}{c}0.407 \\
(0.015)\end{array}$ & $\begin{array}{c}0.420 \\
(0.015)\end{array}$ & -0.013 \\
\hline Head: Cultivator & $\begin{array}{l}0.441 \\
(0.015)\end{array}$ & $\begin{array}{l}0.415 \\
(0.015)\end{array}$ & 0.026 \\
\hline Head: Labourer & $\begin{array}{c}0.340 \\
(0.015)\end{array}$ & $\begin{array}{l}0.343 \\
(0.015)\end{array}$ & -0.003 \\
\hline Landholding (Acres) & $\begin{array}{l}0.456 \\
(0.013)\end{array}$ & $\begin{array}{l}0.443 \\
(0.013)\end{array}$ & 0.013 \\
\hline Area of house and homestead (Acres) & $\begin{array}{c}0.052 \\
(0.001)\end{array}$ & $\begin{array}{c}0.052 \\
(0.002)\end{array}$ & 0.000 \\
\hline Separate toilet in house & $\begin{array}{l}0.564 \\
(0.015)\end{array}$ & $\begin{array}{l}0.608 \\
(0.015)\end{array}$ & -0.044 \\
\hline Own a motorized vehicle & $\begin{array}{l}0.124 \\
(0.010)\end{array}$ & $\begin{array}{l}0.126 \\
(0.010)\end{array}$ & -0.002 \\
\hline Own a Savings Bank Account & $\begin{array}{l}0.447 \\
(0.015)\end{array}$ & $\begin{array}{l}0.475 \\
(0.015)\end{array}$ & -0.028 \\
\hline
\end{tabular}

Notes: Panel A uses data from the houselisting exercise we carried out in 2007. Since 2 of the villages from the 2007 sample had to be replaced due to Maoist violence, Panel A uses a sample of only 46 villages. Panel B uses household survey data from 2010 for all 48 villages for sample households that owned no more than 1.5 acres of land. Standard errors in parentheses. 
Table 2: Agent Characteristics

\begin{tabular}{|c|c|c|c|}
\hline & $\begin{array}{c}\text { GRAIL } \\
(1)\end{array}$ & $\begin{array}{c}\text { TRAIL } \\
(2)\end{array}$ & $\begin{array}{c}\text { Difference } \\
(3)\end{array}$ \\
\hline Male & $\begin{array}{c}1.00 \\
(0.00)\end{array}$ & $\begin{array}{c}0.958 \\
(0.042)\end{array}$ & $\begin{array}{c}0.042 \\
(0.042)\end{array}$ \\
\hline $\mathrm{SC} / \mathrm{ST}$ & $\begin{array}{c}0.208 \\
(0.085)\end{array}$ & $\begin{array}{c}0.083 \\
(0.058)\end{array}$ & $\begin{array}{c}0.125 \\
(0.102)\end{array}$ \\
\hline Non-Hindu & $\begin{array}{c}0.125 \\
(0.069)\end{array}$ & $\begin{array}{c}0.083 \\
(0.058)\end{array}$ & $\begin{array}{c}0.042 \\
(0.090)\end{array}$ \\
\hline General caste & $\begin{array}{c}0.667 \\
(0.098)\end{array}$ & $\begin{array}{c}0.833 \\
(0.078)\end{array}$ & $\begin{array}{c}-0.167 \\
(0.125)\end{array}$ \\
\hline Primary Occupation: Cultivator & $\begin{array}{c}0.375 \\
(0.101)\end{array}$ & $\begin{array}{c}0.042 \\
(0.042)\end{array}$ & $\begin{array}{c}0.33 \\
(0.109)\end{array}$ \\
\hline Primary Occupation: Shop/business & $\begin{array}{c}0.208 \\
(0.095)\end{array}$ & $\begin{array}{c}0.958 \\
(0.042)\end{array}$ & $\begin{array}{c}-0.667 \\
(0.104)\end{array}$ \\
\hline Primary Occupation: Other & $\begin{array}{c}0.417 \\
(0.690)\end{array}$ & $\begin{array}{c}0.000 \\
(0.000)\end{array}$ & $\begin{array}{c}0.125 \\
(0.690)\end{array}$ \\
\hline Owns agricultural land & $\begin{array}{c}2.63 \\
(0.198)\end{array}$ & $\begin{array}{c}3.29 \\
(0.244)\end{array}$ & $\begin{array}{c}-0.667 \\
(0.314)\end{array}$ \\
\hline Total owned land & $\begin{array}{c}4.08 \\
(0.248)\end{array}$ & $\begin{array}{c}5.04 \\
(0.292)\end{array}$ & $\begin{array}{c}-0.958 \\
(0.383)\end{array}$ \\
\hline Has pucca house & $\begin{array}{c}0.375 \\
(0.101)\end{array}$ & $\begin{array}{c}0.458 \\
(0.104)\end{array}$ & $\begin{array}{l}-0.083 \\
(0.145)\end{array}$ \\
\hline Educated above primary school & $\begin{array}{c}0.958 \\
(0.042)\end{array}$ & $\begin{array}{c}0.792 \\
(0.085)\end{array}$ & $\begin{array}{c}0.167 \\
(0.094)\end{array}$ \\
\hline Weekly income (Rupees) & $\begin{array}{l}1102.895 \\
(138.99)\end{array}$ & $\begin{array}{l}1668.75 \\
(278.16)\end{array}$ & $\begin{array}{c}-565.855 \\
(336.78)\end{array}$ \\
\hline Village society member & $\begin{array}{c}0.292 \\
(0.095)\end{array}$ & $\begin{array}{c}0.083 \\
(0.058)\end{array}$ & $\begin{array}{c}0.208 \\
(0.111)\end{array}$ \\
\hline Party hierarchy member & $\begin{array}{c}0.167 \\
(0.078)\end{array}$ & $\begin{array}{l}0.000 \\
(0.00)\end{array}$ & $\begin{array}{c}0.167 \\
(0.079)\end{array}$ \\
\hline Panchayat member & $\begin{array}{c}0.125 \\
(0.069)\end{array}$ & $\begin{array}{l}0.000 \\
(0.00)\end{array}$ & $\begin{array}{c}0.125 \\
(0.069)\end{array}$ \\
\hline Self/family ran for village head & $\begin{array}{c}0.083 \\
(0.058)\end{array}$ & $\begin{array}{l}0.000 \\
(0.00)\end{array}$ & $\begin{array}{c}0.083 \\
(0.058)\end{array}$ \\
\hline
\end{tabular}

Notes: Sample consists of 24 agents in TRAIL villages and 24 agents in GRAIL villages. Standard errors in parenthesis. 


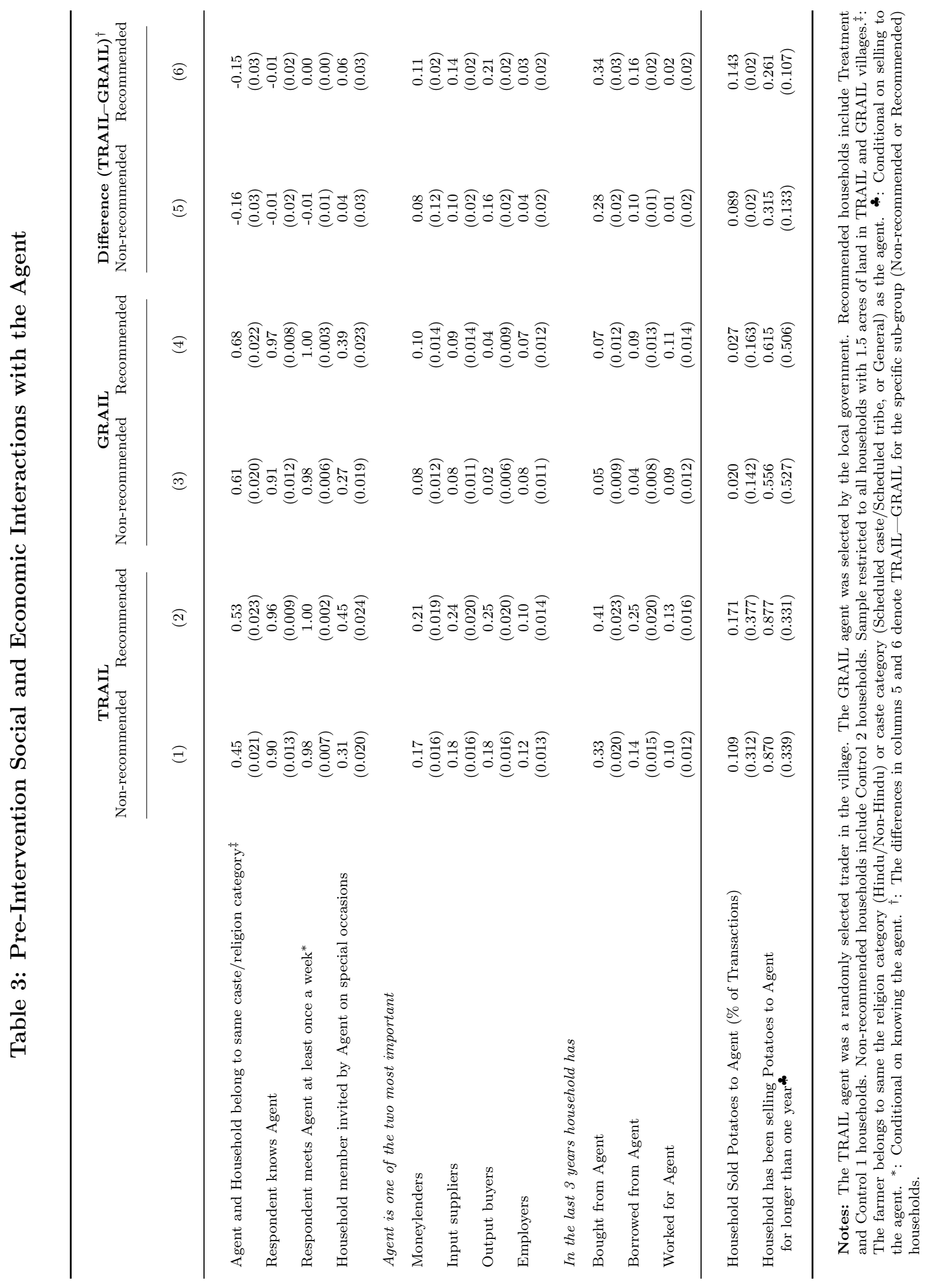


Table 4: Average Treatment Effects on Agricultural Borrowing, Farm Value Added, Non Agricultural Income and Total Household Income

\begin{tabular}{|c|c|c|c|c|c|}
\hline & \multicolumn{2}{|c|}{ Agricultural Loans } & \multirow{3}{*}{$\begin{array}{c}\text { Farm } \\
\text { Value Added } \\
\text { (Rs.) }\end{array}$} & \multicolumn{2}{|c|}{ Income } \\
\hline & All & Non-Program $^{\dagger}$ & & Non Agricultural & Household \\
\hline & (Rs.) & (Rs.) & & (Rs.) & (Rs.) \\
\hline & (1) & $(2)$ & $(3)$ & $(4)$ & $(5)$ \\
\hline TRAIL Treatment & $\begin{array}{c}2868 \\
(658.90)\end{array}$ & $\begin{array}{l}-448.50 \\
(634.80)\end{array}$ & $\begin{array}{l}2147.874 \\
(723.935)\end{array}$ & $\begin{array}{c}1506.785 \\
(3655.543)\end{array}$ & $\begin{array}{c}5612.479 \\
(4125.591)\end{array}$ \\
\hline Mean TRAIL C1 & 2096 & 2096 & 10336.511 & 33617.764 & 49765.238 \\
\hline$\%$ Effect TRAIL & 136.83 & -21.39 & 20.779 & 4.482 & 11.278 \\
\hline GRAIL Treatment & $\begin{array}{c}2754 \\
(593.40)\end{array}$ & $\begin{array}{l}-104.90 \\
(551.30)\end{array}$ & $\begin{array}{c}138.905 \\
(929.675)\end{array}$ & $\begin{array}{l}-4326.522 \\
(3225.654)\end{array}$ & $\begin{array}{l}-5434.789 \\
(4496.421)\end{array}$ \\
\hline Mean GRAIL C1 & 1931 & 1931 & 10501.064 & 37170.751 & 56082.489 \\
\hline$\%$ Effect GRAIL & 142.62 & -5.43 & 1.323 & -11.640 & -9.691 \\
\hline $\begin{array}{l}\text { TRAIL v. GRAIL } \\
\text { Treatment }\end{array}$ & $\begin{array}{c}114.50 \\
(890.60)\end{array}$ & $\begin{array}{l}-343.6 \\
(842.6)\end{array}$ & $\begin{array}{c}2008.969 \\
(1183.349)\end{array}$ & $\begin{array}{c}5833.307 \\
(4879.593)\end{array}$ & $\begin{array}{l}11047.268 \\
(6110.838)\end{array}$ \\
\hline Sample Size & 6,156 & 6,156 & 6,156 & 6,159 & 6,156 \\
\hline
\end{tabular}

Notes: Treatment effects are computed from regressions that follow equation (1) in the text and are run on household-year level data for all sample households in TRAIL and GRAIL villages with at most 1.5 acres of land. Regressions also control for the religion and caste of the household, age, educational attainment and occupation of the eldest male member of the household, household's landholding, a set of year dummies and an information village dummy. \% Effect: Treatment effect as a percentage of the mean of the relevant Control 1 group. ${ }^{\dagger}$ : Non-Program loans refer to loans from sources other than the TRAIL or GRAIL schemes. Standard errors in parentheses are clustered at the hamlet level. . 


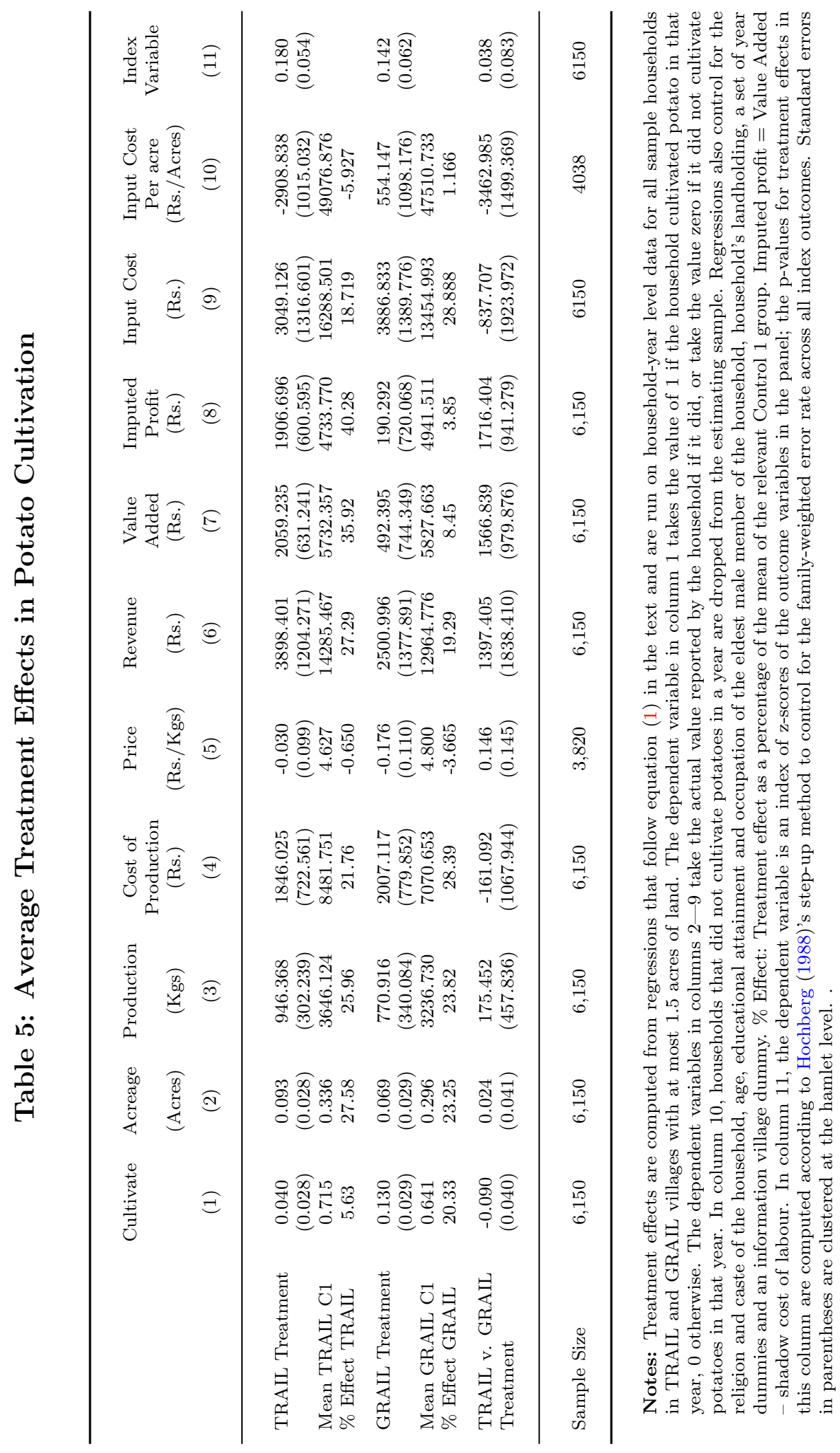


Table 6: Loan Performance

\begin{tabular}{lcc}
\hline & $\begin{array}{c}\text { Take-up } \\
(1)\end{array}$ & $\begin{array}{c}\text { Default } \\
(2)\end{array}$ \\
\hline & & \\
Panel A: Sample Means & & \\
TRAIL & 0.937 & 0.070 \\
& $(0.006)$ & $(0.007)$ \\
GRAIL & 0.872 & 0.070 \\
& $(0.009)$ & $(0.008)$ \\
Difference (TRAIL-GRAIL) & 0.065 & 0.000 \\
& $(0.011)$ & $(0.010)$ \\
\hline
\end{tabular}

Panel B: Regression Results

\begin{tabular}{lcc} 
GRAIL & -0.066 & 0.005 \\
& $(0.011)$ & $(0.010)$ \\
\hline & & \\
$R^{2}$ & 0.08 & 0.05 \\
Sample Size & 2667 & 2422 \\
\hline
\end{tabular}

Notes: The sample consists of household-cycle level observations of Treatment households in TRAIL and GRAIL villages with at most 1.5 acres of landholding. The dependent variable in column 1 takes value 1 if the household took the program loan in the particular cycle, provided the household was eligible for the loan in that cycle. The dependent variable in column 2 takes value 1 if a borrowing household fails to fully repay the amount due on the loan taken in that cycle on the due date. The regression specification In Panel $\mathrm{B}$ is given by equation (2). Regressions also control for landholding, religion and caste of the household and age and educational attainment of the oldest male in the household. Robust standard errors. 
Table 7: Variation of Productivity with Observable Household Characteristics

\begin{tabular}{|c|c|}
\hline \multicolumn{2}{|l|}{ Regression Results } \\
\hline Landholding & $\begin{array}{c}1.103 \\
(0.115)\end{array}$ \\
\hline Non Hindu & $\begin{array}{c}-0.157 \\
(0.147)\end{array}$ \\
\hline Low Caste & $\begin{array}{c}-0.110 \\
(0.120)\end{array}$ \\
\hline Household Size & $\begin{array}{c}0.019 \\
(0.021)\end{array}$ \\
\hline Female-headed Household & $\begin{array}{l}-0.457 \\
(0.217)\end{array}$ \\
\hline Age of Oldest Male & $\begin{array}{c}-0.004 \\
(0.003)\end{array}$ \\
\hline Oldest Male: Completed Primary School & $\begin{array}{c}0.080 \\
(0.084)\end{array}$ \\
\hline Constant & $\begin{array}{c}1.212 \\
(0.188)\end{array}$ \\
\hline $\begin{array}{l}\text { Sample Size } \\
\text { R-squared }\end{array}$ & $\begin{array}{l}1,000 \\
0.163\end{array}$ \\
\hline \multicolumn{2}{|l|}{ Descriptives on farm productivity } \\
\hline $\begin{array}{l}\text { Mean of Productivity } \\
\text { SD of Productivity } \\
\text { Minimum Productivity } \\
\text { Productivity Quartile 25\% } \\
\text { Productivity Quartile 50\% } \\
\text { Productivity Quartile } 75 \% \\
\text { Maximum Productivity }\end{array}$ & $\begin{array}{c}1.707 \\
1.148 \\
-1.294 \\
0.811 \\
2.014 \\
2.638 \\
3.702\end{array}$ \\
\hline
\end{tabular}

Notes: The dependent variable is the household productivity estimate. Standard errors in parentheses are clustered at the hamlet level. The etimating sample includes cultivator Control 1 and Control 2 households in TRAIL and GRAIL villages with at most 1.5 acres of land. 
Table 8: Effect of Treatment on Voting Patterns in Straw Poll

\begin{tabular}{lccc}
$\begin{array}{l}\text { Average } \\
\text { TRAIL }\end{array}$ & GRAIL & TRAIL & $\begin{array}{l}\text { Heterogeneous Treatment Effect } \\
\text { TRARAIL }\end{array}$ \\
\hline
\end{tabular}

(1)

$(2)$

(3)

(4)

Treatment Effect

$\begin{array}{cc}0.0241 & 0.0782 \\ (0.0496) & (0.0340)\end{array}$

Treatment Effect: Bin 1

Treatment Effect: Bin 2

Treatment Effect: Bin 3

$\begin{array}{cc}0.0915 & 0.130 \\ (0.0868) & (0.0697) \\ -0.0741 & 0.0309 \\ (0.0805) & (0.0702) \\ 0.0568 & 0.0135 \\ (0.0564) & (0.0743)\end{array}$

Selection Effect

$\begin{array}{lc}-0.0649 & 0.0825 \\ (0.0447) & (0.0369)\end{array}$

Selection Effect: Bin 1

$\begin{array}{cc}-0.133 & 0.0217 \\ (0.0610) & (0.0580)\end{array}$

Selection Effect: Bin 2

$-0.0291$

0.117

$(0.0738)$

$(0.0664)$

Selection Effect: Bin 3

$-0.0343$

0.105

(0.0594)

(0.0718)

Sample Size

1,011

1,026

1,021

1,044

Notes: Estimating sample includes all sample households in TRAIL and GRAIL villages with atmost 1.5 acres of land. OLS regression results presented. Standard errors in parenthesis clustered at the hamlet level. Estimating sample includes all sample households in TRAIL and GRAIL villages with at most 1.5 acres of land. Productivity computed using logarithm of acreage under potato cultivation. 


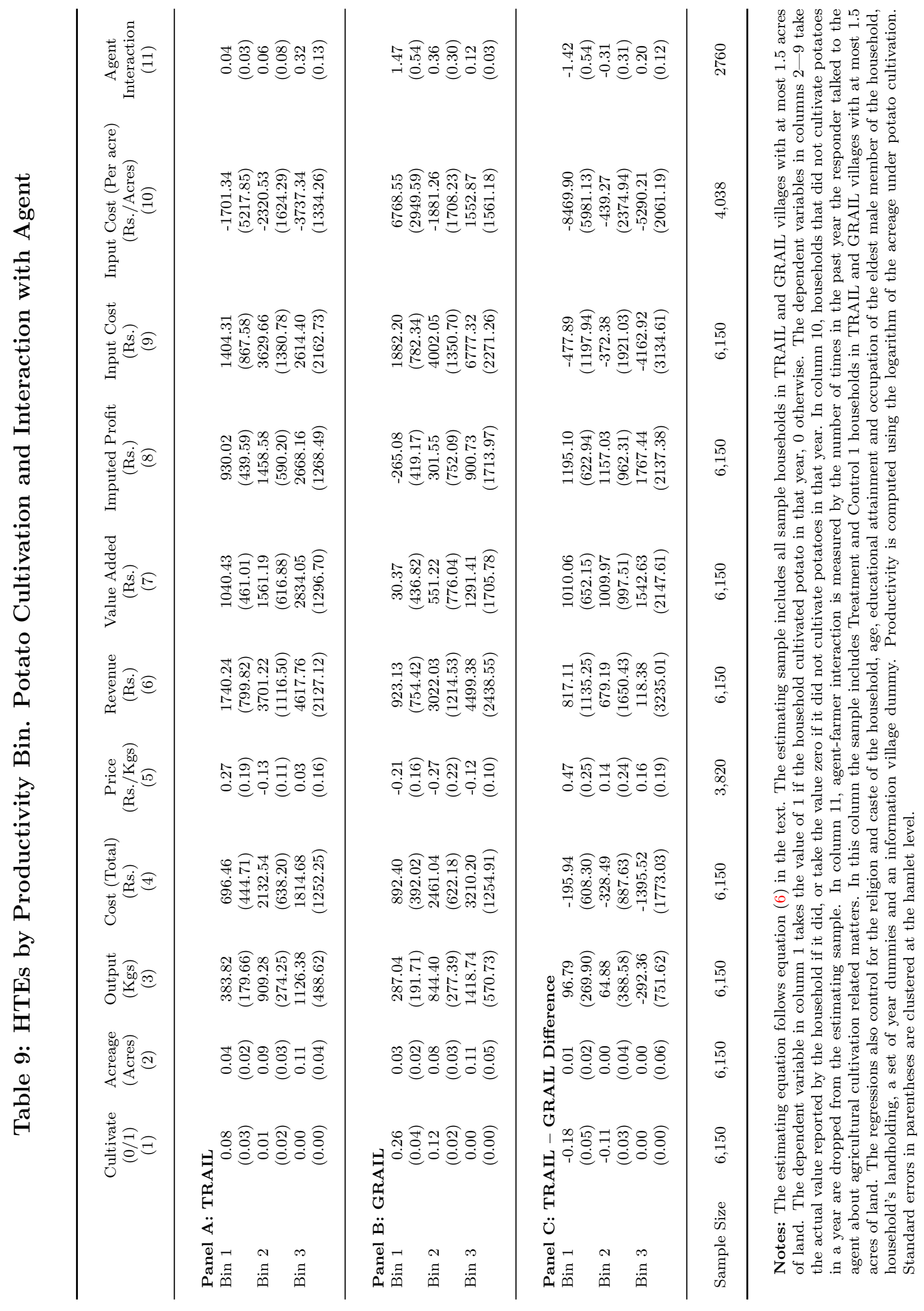




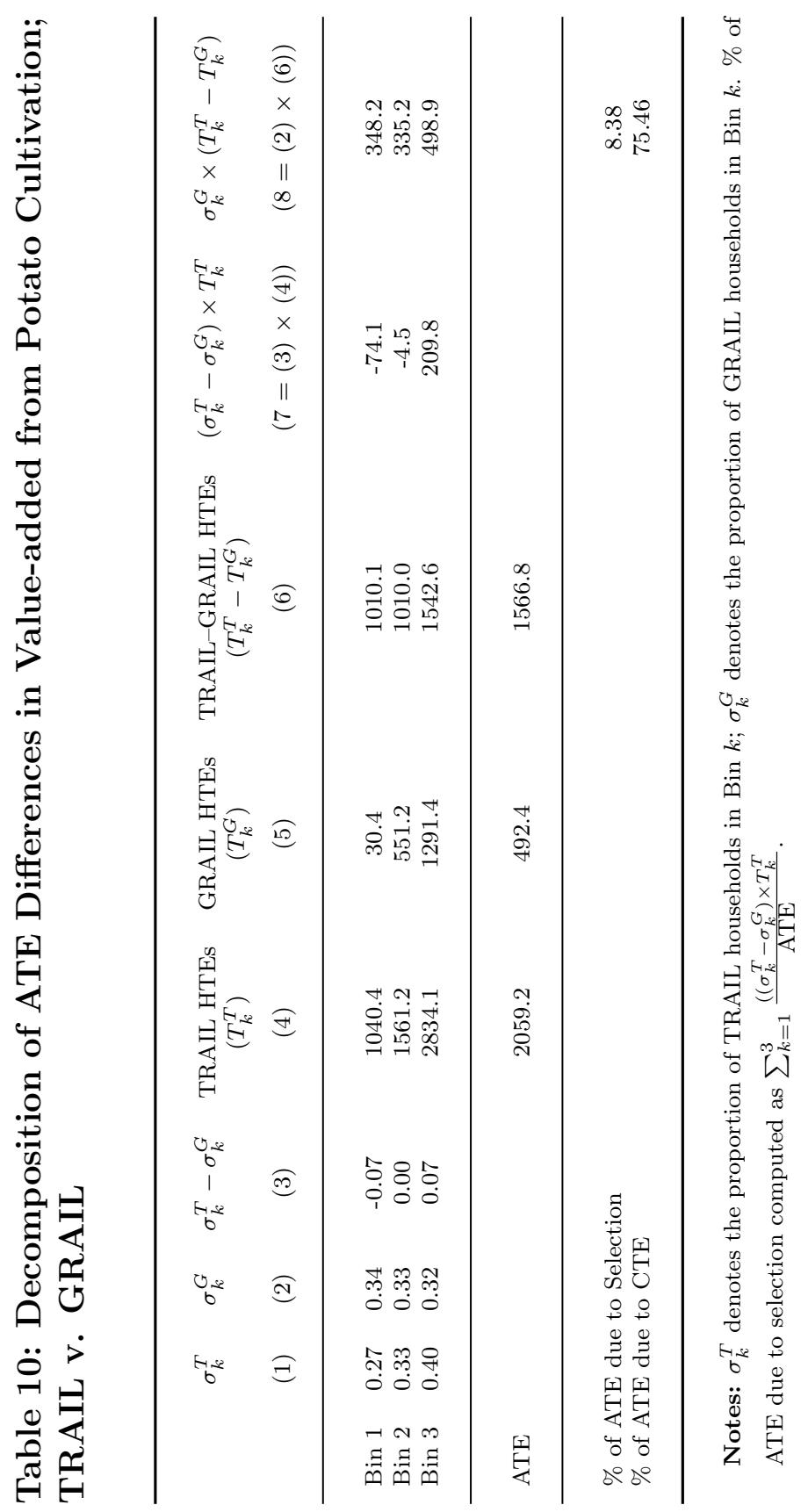


Table 11: Estimates from the Multidimensional Screening Model

\begin{tabular}{|c|c|c|}
\hline Variable & TRAIL & GRAIL \\
\hline (1) $\zeta$ & \multicolumn{2}{|c|}{-0.076} \\
\hline (2) $\Delta$ & 0.21 & 0.28 \\
\hline (3) $\quad \mu$ (Fixed Effect Estimate $\left.{ }^{\dagger}\right)$ & \multicolumn{2}{|c|}{1.39} \\
\hline \multicolumn{3}{|l|}{ Reduced Form Estimates: } \\
\hline $\begin{array}{l}\text { (4) Quasi Profit: } \frac{\mu}{1+\zeta} R_{i v t}-C_{i v t} \\
\text { (5) } \text { Predicted ATE: }\left[\frac{\mu}{1+\zeta} R_{i v t}-C_{i v t}\right] \times \Delta\end{array}$ & $\begin{array}{c}13008.29 \\
2731.74\end{array}$ & $\begin{array}{c}12432.64 \\
3481.14\end{array}$ \\
\hline
\end{tabular}

Structural Estimates:
(6) $\quad\left[a_{i}\left[\frac{w_{i}}{c_{i}}\right]^{\frac{\mu}{1+\zeta}}-\frac{w_{i}}{\left(c_{i}\right)^{\frac{1}{1+\zeta}}}\right] \times \Delta \quad 1.35 \quad 1.46$
(7) Percentage Effect on Value Added $\quad 36.48 \quad 33.48$

(8) $\quad \mu\left(\right.$ IV Estimate Es$\left.^{\ddagger}\right)$

0.90

Reduced Form Estimates:

(9) Quasi Profit: $\frac{\mu}{1+\zeta} R_{i v t}-C_{i v t} \quad 5432.67 \quad 5557.38$

(10) Predicted ATE: $\left[\frac{\mu}{1+\zeta} R_{i v t}-C_{i v t}\right] \times \Delta \quad 1140.86 \quad 1556.07$

Structural Estimates:

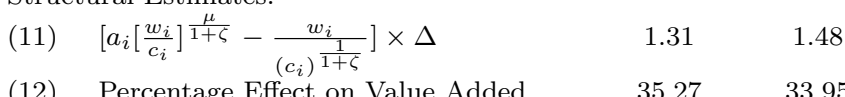

(12) Percentage Effect on Value Added $\quad 35.27 \quad 33.95$

Notes: ${ }^{\dagger}$ : Estimate of $\mu$ obtained from a household fixed effects regression of log quantity of potato cultivates on log acreage and villageyear dummies. Sample includes Control 1 and Control 2 households in TRAIL and GRAIL villages with at most 1.5 acres of land. ‡: Estimate of $\mu$ obtained from a regression of average productivity on log acreage, household fixed effects and village-year dummies, with the treatment dummy as the instrument. $\Delta$ defined as the proportional increase in the cost of cultivation owing to the treatment defined by the treatment effect as a proportion of the Mean for Control 1 households in column 4 of Table $5 . R$ and $C$ defined by the mean Revenue and Cost of cultivation for Control 1 households in columns 6 and 4 of Table 5. Sample includes Treatment and Control 1 households in TRAIL and GRAIL villages with at most 1.5 acres of land. 


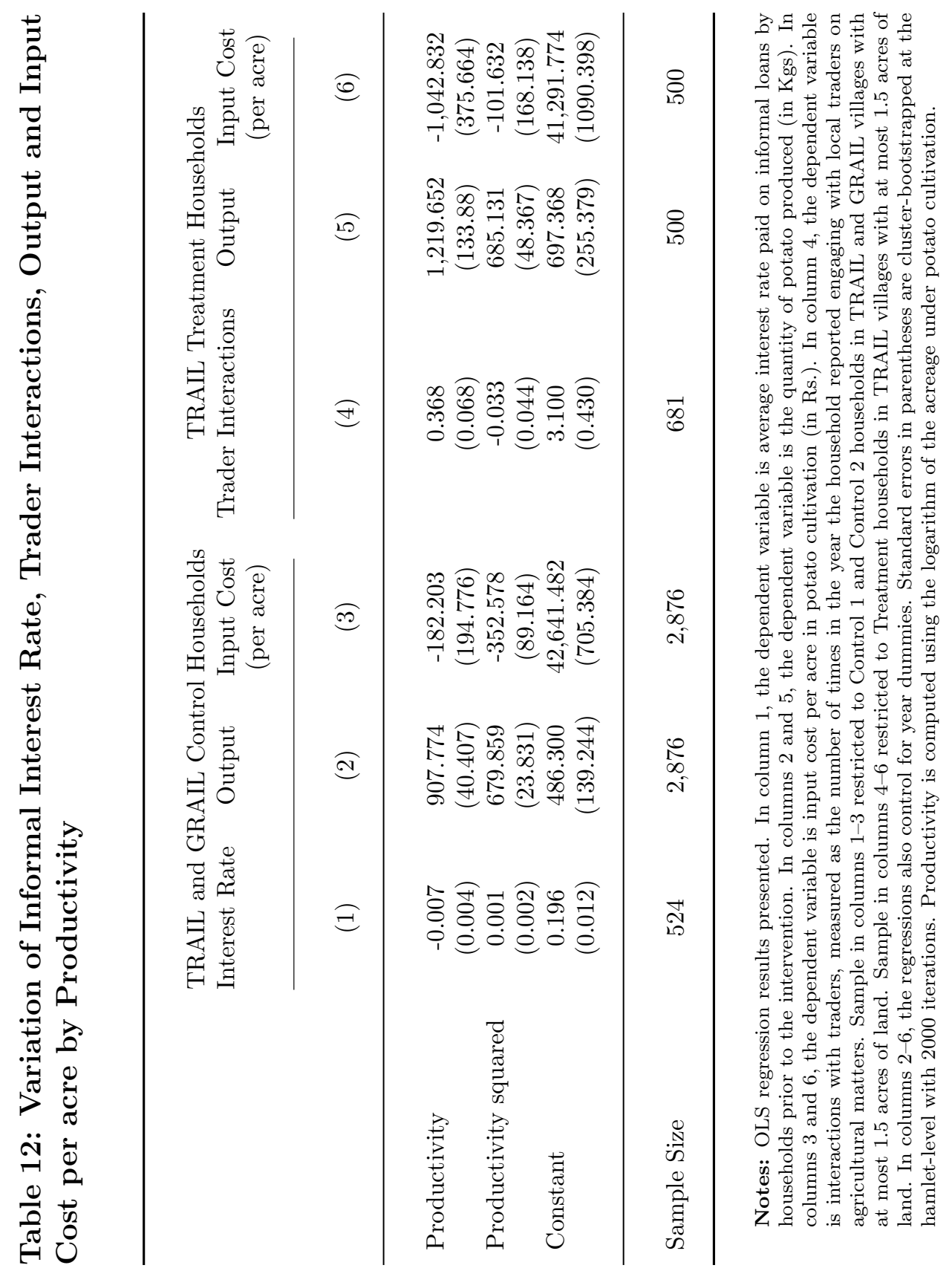




\section{Online Appendix}

\section{A1 Multidimensional Screening with Credit Rationing}

Below we sketch the alternative model where agents screen farmers of multidimensional types, in the presence of credit rationing. We use the predictions of this model to empirically examine whether this mechanism can provide an alternative explanation of our result of larger average treatment effects in the TRAIL scheme.

Farmers (indexed by $i$ ) can vary in three different dimensions of type: wealth, ability and cost. All farmers face binding credit constraints in the informal credit market, so their scale of cultivation is determined by their credit access, which is an increasing function of their wealth type. Output is increasing in the scale of cultivation, with a constant elasticity $\mu$ which may exceed or be smaller than one, so we impose no restrictions on returns to scale. Output also depends on productivity, which depends on the farmer's ability type. Finally, unit costs of cultivation vary for a given farmer with the scale of cultivation with a constant elasticity $\zeta$. Cultivation costs vary across farmers according to the third dimension of heterogeneity, their cost type. We impose no constraints on the joint distribution of wealth, ability and cost.

Since credit constraints bind, the scale of cultivation is not chosen by farmers and depends on their wealth type, which is exogenously assigned. The farmer's financing constraint determines the upper bound on what the farmer can spend on cultivation cost. Since financing constraints bind by assumption, the actual cultivation cost equals the financing constraint. The farmers financial access (from self-financing as well as access to credit) therefore determines the actual cultivation cost:

$$
\log C_{i v t}=\log w_{i}+\log \gamma_{v t}+\epsilon_{4 i v t}
$$

where $C_{i v t}$ denotes the total cultivation cost of a control farmer $i$ in village-year $v, t, w_{i}$ is a measure of credit access or wealth, and $\gamma_{v t}$ represents village and year dummies for shocks to the supply of credit. Hence farmer fixed effects in the panel regression (A1) provide a measure of wealth.

Let $u_{i v t}$ denote the unit cultivation cost of farmer $i$ in village-year $v, t$. This in turn depends on the farmer's cost type $c_{i}$ and the area cultivated $l_{i v t}$ (owing to pecuniary scale economies or diseconomies), according to

$$
\log u_{i v t}=\log c_{i}+\log q_{v t}+\zeta \log l_{i v t}+\epsilon_{3 i v t}
$$

where $\log q_{v t}$ denotes input price shocks in $(v, t)$. On the other hand, the relationship between total and unit cultivation costs is given by

$$
C_{i v t} \equiv u_{i v t} l_{i v t} q_{v t}
$$

Given $C_{i v t}$ the financial access of the farmer, (A2) and (A3) represent two equations in 
two unknowns (unit cost, and scale of cultivation). Solving these, the scale of cultivation is determined by

$$
\log l_{i v t}=\frac{1}{1+\zeta}\left[\log c_{i v t}-\log c_{i}-\log q_{v t}\right]=\frac{1}{1+\zeta}\left[\log w_{i}-\log c_{i}-\log q_{v t}+\log \gamma_{v t}\right]+\epsilon_{4 i v t}
$$

i.e., by the wealth and cost type of the farmer, in conjunction with village and year shocks in the supply of credit and input prices.

Finally, we can estimate farmer ability $a_{i}$ as a fixed effect in a panel production function regression:

$$
\log y_{i v t}=\log a_{i}+\mu \log l_{i v t}+\delta_{2 v t}+\epsilon_{2 i v t}
$$

where $y_{i v t}$ denotes revenue of farmer $i$ in village $v$ in year $t, \mu$ represents returns to scale, and $\delta_{2 v t}$ denotes village and year dummies representing village level productivity shocks.

\section{Selection Patterns}

The three type variables are estimated as farmer fixed effects in panel regressions (A1, A2, A5) respectively. We can then directly check selection in either TRAIL and GRAIL on any of the three dimensions by comparing the corresponding distribution of each dimension between control 1 and 2 subjects.

\section{Predicted Treatment Effects}

Under the assumption of no treatment effects per se on farmer wealth, ability or cost, we can estimate the treatment effect of either program (TRAIL or GRAIL) and the difference between these treatment effects implied by selection differences on the three dimensions: wealth, ability and cost.

Let $\Delta>0$ denote the percent change in financial access resulting from the treatment, so that $\log C_{i v t}$ rises by $\Delta$. Dropping the regression error terms, the resulting expressions for post-treatment log acreage and log unit cost are:

$$
\begin{gathered}
\log l_{i v t}=\frac{1}{1+\zeta}\left[\Delta+\log w_{i}+\log \gamma_{v t}-\log q_{v t}-\log c_{i}\right] \\
\log u_{i v t}=\frac{\zeta}{1+\zeta}\left[\Delta+\log w_{i}+\log \gamma_{v t}\right]+\frac{1}{1+\zeta}\left[\log c_{i}+\log q_{v t}\right]
\end{gathered}
$$

Denoting (total) cost by $C_{i v t}$, the reduced form for log cost is therefore

$$
\log C_{i v t} \equiv \log l_{i v t}+\log u_{i v t}=\Delta+\log w_{i}+\log \gamma_{v t}
$$

Hence the treatment effects on these three variables are:

$$
d \log l_{i v t}=\frac{1}{1+\zeta} \Delta, d \log u_{i v t}=\frac{\zeta}{1+\zeta} \Delta, d \log C_{i v t}=\Delta
$$


The resulting treatment effect on log revenues is

$$
d \log R_{i v t}=\mu d \log l_{i v t}=\frac{\mu}{1+\zeta} \Delta
$$

and on farm profit is

$$
d \Pi_{i v t} \equiv d R_{i v t}-d C_{i v t}=\left[\frac{\mu}{1+\zeta} R_{i v t}-C_{i v t}\right] \Delta
$$

The difference in predicted treatment effect between TRAIL and GRAIL is thus equal to the difference between average quasi-profit $\left[\frac{\mu}{1+\zeta} R_{i v t}-C_{i v t}\right]$ of the respective Control 1 subjects. To relate quasi-profit to underlying types of the farmers, observe that the model implies

$$
\frac{\mu}{1+\zeta} R_{i v t}-C_{i v t}=a_{i}\left[\frac{w_{i} \gamma_{v t}}{c_{i} q_{v t}}\right]^{\frac{\mu}{1+\zeta}}-\frac{w_{i} \gamma_{v t}}{\left(c_{i} q_{v t}\right)^{\frac{1}{1+\zeta}}}
$$

so if we normalize the village year shocks to their unit mean, this reduces to

$$
a_{i}\left[\frac{w_{i}}{c_{i}}\right]^{\frac{\mu}{1+\zeta}}-\frac{w_{i}}{\left(c_{i}\right)^{\frac{1}{1+\zeta}}}
$$

which we can calculate for each control 1 farmer from the estimated types on the three dimensions ability $\left(a_{i}\right)$, wealth $\left(w_{i}\right)$ and cost $\left(c_{i}\right)$. 


\section{A2 Model Of Agent-Farmer Interactions: Details}

\section{Control Farmers}

A contract between farmer $F$ of ability $\theta$ and trader $T$ is represented by a scale of cultivation $l$, help $h$, monitoring $m$, an interest rate $r$ and a side-payment $s$. The first three determine the size of the loan $c(h, m) l$. The farmer repays the loan if his crop succeeds. Hence the farmer's expected payoff (excluding fixed cost $F$ ) is

$$
p(\theta, m)[a(\theta, m) f(l)-(1+r) c(h, m) l]+s
$$

while the trader's payoff is

$$
\tau p(\theta, m) a(\theta, m) f(l)+[(1+r) p(\theta, m)-(1+\rho)] c(h, m) l-\gamma_{T}(m+h)-s
$$

where $\tau$ represents an exogenous middleman margin earned by the trader per unit output. An efficient contract maximizes the joint payoff given by

$$
(1+\tau) A(\theta, m) f(l)-(1+\rho) c(h, m) l-\gamma_{T}[m+h]
$$

It is optimal for the trader to not monitor the farmer at all $\left(m^{c}(\theta)=0\right)$, since monitoring is costly, lowers expected productivity $A$ and increases the production cost. Next, observe that given a certain level of help $h$, the optimal scale of cultivation $l^{c}(\theta, h)$ which maximizes

$$
(1+\tau) A(\theta, 0) f(l)-(1+\rho) c(h, 0) l
$$

is increasing in $\theta$ and $h$. Let the maximized value of the expression in equation (A17) be denoted by $\Pi(h, \theta)$. Then help $h^{c}(\theta)$ is chosen to maximize

$$
\Pi(h, \theta)-\gamma_{T} h
$$

By the Envelope Theorem, $\Pi$ is a supermodular function: the marginal return to help increases with the farmer's ability. ${ }^{50}$ Hence $h^{c}(\theta)$ is increasing: higher ability farmers receive more help, and end up with higher scale of cultivation, productivity, and lower unit cost. This rationalizes our use of scale of cultivation as a proxy for ability and for productivity among control farmers.

Observe also that the choice of scale of cultivation can be delegated to the farmer, if the interest rate is set at

$$
1+r^{c}(\theta)=\frac{1+\rho}{(1+\tau) p(\theta, 0)}
$$

This interest rate adjusts the cost of capital up for default risk, and then subsidized by the trader in order to induce the farmer to internalize the effect of cultivation scale on T's profits. Hence we obtain predictions (i) and (ii).

\footnotetext{
${ }^{50}$ This is because $\Pi_{h}$ equals $-\rho c_{h}(h, 0) l^{c}(\theta, h)$ which is rising in $\theta$.
} 


\section{TRAIL Treatment Effects}

In TRAIL, a trader is appointed the agent, and recommends borrowers for TRAIL loans. These loans are offered at interest rate $r_{T}$, which is lower than the informal cost of capital for traders $\rho$. Agents earn a commission of $\psi \in(0,1)$ per rupee interest paid by the borrowers they recommended. We assume that any farmer whom the agent selects is already committed to cultivating $l^{c}$, financed by informal loans taken before the TRAIL loan was offered to him/her. ${ }^{51}$ As a result the TRAIL loan finances an increase in the cultivation scale. ${ }^{52}$ This applies to farmers in productivity Bins 2 and 3; for those in Bin 1 there are no pre-existing plans for cultivating potatoes. In what follows, we present calculations for farmers in Bins 2 and 3; for those in Bin 1 we set the pre-existing cultivation scale $L^{c}(\theta)$ to zero.

The efficient contract between $T$ and $F$ will now involve a supplementary cultivation scale of $l^{t}$, resulting in total scale of $l^{T} \equiv l^{c}+l^{t}$. The levels of monitoring and help will be adjusted to $m^{T}, h^{T}$. Then the joint payoff of $T$ and $F$ is

$$
(1+\tau) A(\theta, m) f\left(L^{c}(\theta)+l^{t}\right)-\left[(1+\rho) L^{c}(\theta)+\left\{1+r_{T}(1-\psi)\right\} p(\theta, m) l^{t}\right] c(h, m)-\gamma_{T}[h+m]
$$

where $L^{c}(\theta) \equiv l^{c}\left(\theta, h^{c}(\theta)\right)$.

The TRAIL agent continues to find it optimal not to monitor the farmer: $m^{T}(\theta)=0$. Given help $h$, the treatment effect on cultivation scale $l^{t}(\theta, h)$ maximizes

$$
(1+\tau) A(\theta, 0) f\left(L^{c}(\theta)+l^{t}\right)-\left[(1+\rho) L^{c}(\theta)+p(\theta, 0)\left\{1+r_{T}(1-\psi)\right\} l^{t}\right] c(h, m)
$$

and therefore it also maximizes

$$
(1+\tau) a(\theta, 0) f\left(L^{c}(\theta)+l^{t}\right)-\left[\left\{1+r_{T}(1-\psi)\right\} l^{t}\right] c(h, m)
$$

Using the same argument as used in Lemma 2 in Maitra et al. (2017), the cultivation treatment effect $l^{t}(., h)$ is increasing in $\theta$. The Envelope Theorem implies that the help provided by the agent to the treated farmer $h^{T}(\theta)$ must satisfy the first order condition

$$
\left[(1+\rho) L^{c}(\theta)+\left\{1+r_{T}(1-\psi)\right\} p(\theta, 0) l^{t}\left(\theta, h^{T}(\theta)\right)\right] c_{h}\left(h^{T}(\theta), 0\right)+\gamma_{T}=0 .
$$

The corresponding second order condition implies that $h^{T}(\theta)$ is increasing. Among treated farmers the more able will receive more help, and thereby attain lower unit costs, cultivate a larger scale, and produce higher output: hence the Order Preserving Assumption holds in TRAIL.

We can also compare agent interactions between treated and control farmers with the same ability $\theta$. Help $h^{c}(\theta)$ provided to a control farmer with the same ability satisfies

\footnotetext{
${ }^{51}$ This is in order to explain the lack of treatment effects on informal borrowing.

${ }^{52}$ Recall that in Table 4 we did not see any evidence that the TRAIL loans crowded out informal loans.
} 
the first order condition

$$
\left[(1+\rho) L^{c}(\theta)\right] c_{h}\left(h^{c}(\theta), 0\right)+\gamma_{T}=0 .
$$

Comparing (A23) and (A24), it is evident that $h^{T}(\theta) \geq h^{c}(\theta)$, so treated farmers obtain more help. The reason is that they cultivate a larger area compared to control farmers with the same ability, so the gains from unit cost reductions generate a larger reduction in total cost, which motivates the agent to provide more help. In turn this implies treated farmers cultivate a larger area, produce more output and earn more profits compared with control farmers of the same ability. This is prediction (iv).

\section{GRAIL Treatment Effects}

In the GRAIL scheme, the political incumbent appoints an agent who is not a trader. This agent does not lend, or trade in inputs or crop output, and so does not have the same business-related incentives as a TRAIL agent. Instead, his objectives are political or ideological, represented by welfare weight $v(\theta)$, and seeks to maximize $v(\theta) p(\theta, m)-\gamma_{G} m$. The welfare weight also includes the commission earned by the agent. While this may bias the agent in favor of selecting more able borrowers because they select larger loans and are less likely to default, we assume this is outweighed by political considerations which bias them in favor of less able farmers, so $v$ is a decreasing function. The optimal level of monitoring (positive if $\gamma_{G}$ is small enough) satisfies

$$
v(\theta) p_{m}\left(\theta, m^{G}(\theta)\right)=\gamma_{G}
$$

Since monitoring is more effective when farmers are less able, and the welfare weights are decreasing in ability, $m^{G}(\theta)$ is decreasing in ability, and is greater that $m^{T}(\theta)=0$. This implies prediction (vi): the GRAIL agent interacts less with high ability farmers. And default rates on GRAIL loans are lower than on TRAIL loans: $p\left(\theta, m^{G}(\theta)\right) \geq p(\theta, 0)$.

Monitoring by the GRAIL agent affects the payoffs of treated farmers and the trader they contract with. Their joint payoff is given by

$$
\begin{aligned}
& \left.(1+\tau) A\left(\theta, m^{G}(\theta)+m\right)\right) f\left(L^{c}(\theta)+l^{g}\right)-\left[(1+\rho) L^{c}(\theta)\right. \\
+ & \left.\left\{1+r_{T}\right\} p\left(\theta, m^{G}(\theta)+m\right) l^{g}\right] c\left(h, m^{G}(\theta)+m\right)-\gamma_{T}[h+m]
\end{aligned}
$$

where $l^{g}$ denotes the additional area that the GRAIL treated farmer cultivates, and $(h, m)$ continues to denote help and monitoring activities of the trader. The commission does not enter this expression since it accrues to the GRAIL agent rather than the trader. The trader has no incentive to monitor. Hence the contract involves a treatment effect $l^{g}$ on area cultivated and help $h$ which maximize

$$
\left.(1+\tau) A\left(\theta, m^{G}(\theta)\right)\right) f\left(L^{c}(\theta)+l^{g}\right)-\left[(1+\rho) L^{c}(\theta)+\left\{1+r_{T}\right\} p\left(\theta, m^{G}(\theta)\right) l^{g}\right] c\left(h, m^{G}(\theta)\right)-\gamma_{T} h
$$


$l^{g}(\theta, h)$ must then maximize

$$
\left.(1+\tau) a\left(\theta, m^{G}(\theta)\right)\right) f\left(L^{c}(\theta)+l^{g}\right)-\left[\left\{1+r_{T}\right\} l^{g}\right] c\left(h, m^{G}(\theta)\right)
$$

while help $h^{G}(\theta)$ minimizes

$$
\left[(1+\rho) L^{c}(\theta)+\left\{1+r_{T}\right\} p\left(\theta, m^{G}(\theta)\right) l^{g}\left(\theta, h^{G}(\theta)\right)\right] c\left(h, m^{G}(\theta)\right)+\gamma_{T} h
$$

Arguments similar to those used for TRAIL treated subjects imply that higher ability farmers receive more help. To see this, note that if $l^{g}(\theta ; h)$ denotes the area treatment effect in GRAIL for any given help $h$, the same argument (combined with $m^{G}$ (.) decreasing) implies $l^{g}(,, h)$ is increasing in $\theta$. Hence $h^{G}(\theta)$ satisfies the first order condition

$$
\left[(1+\rho) L^{c}(\theta)+\left\{1+r_{T}\right\} p\left(\theta, m^{G}(\theta)\right) l^{g}\left(\theta, h^{G}(\theta)\right)\right] c_{h}\left(h^{G}(\theta), m^{G}(\theta)\right)+\gamma_{T}=0
$$

$c_{h m}=0$ then implies that $c_{h}\left(h^{G}(\theta), m^{G}(\theta)\right)=c_{h}\left(h^{G}(\theta), 0\right)$ and the second order condition for minimization of (A30) implies $h^{G}($.$) is increasing. Hence the Order Preserving$ Assumption is also satisfied in GRAIL: treated farmers of higher ability have lower unit cost, cultivate larger area and produce more output. This is the second part of prediction (v). The first part follows from the greater monitoring in the GRAIL scheme.

Observe next that the HTE on area cultivated is higher in TRAIL, for any $\theta$. This follows from comparing maximization problems (A22) and (A28), and using $a\left(\theta, m^{G}(\theta)\right) \leq$ $a(\theta, 0),\left\{1+r_{T}\right\}>\left\{1+r_{T}(1-\psi)\right\}$ and $c\left(h, m^{G}(\theta)\right) \geq c(h, 0)$.

To obtain prediction (vi), compare the first order conditions (A23) and (A30) for help provided by the trader to treated farmers in TRAIL and GRAIL. If

$$
p(\theta, 0)\left\{1+r_{T}(1-\psi)\right\} l^{t}\left(\theta, h^{T}(\theta)\right)>p\left(\theta, m^{G}(\theta)\right)\left\{1+r_{T}\right\} l^{g}\left(\theta, h^{G}(\theta)\right)
$$

more help will be provided to TRAIL treated farmers, who will then end up with lower unit costs, higher output and profits than GRAIL treated farmers of the same ability (because the latter are less productive and incur higher unit costs).

Finally we show (A31) holds if the production function has constant elasticity $f(l)=$ $l^{\alpha}$ where $\alpha \in(0,1)$. Since $A(\theta, m)$ is falling in $m$ and $c(\theta, m)$ is rising in $m$, it follows that

$$
\frac{A\left(\theta, m^{G}(\theta)\right)}{c\left(\theta, m^{G}(\theta)\right)} \leq \frac{A(\theta, 0)}{c(\theta, 0)}
$$

This implies

$$
\frac{p\left(\theta, m^{G}(\theta)\right)}{p(\theta, 0)} \leq\left[\frac{a(\theta, 0) c\left(h, m^{G}(\theta)\right)}{a\left(\theta, m^{G}(\theta)\right) c(h, 0)}\right]
$$

Since the right-hand-side of (A33) is larger than one:

$$
\frac{p\left(\theta, m^{G}(\theta)\right)}{p(\theta, 0)} \leq\left[\frac{a(\theta, 0) c\left(h, m^{G}(\theta)\right)}{a\left(\theta, m^{G}(\theta)\right) c(h, 0)}\right]^{\frac{1}{1-\alpha}}
$$


From the respective first-order conditions for maximization of (A22) and (A28), and using $f(l)=l^{\alpha}$, we have

$$
\frac{a(\theta, 0) c\left(h, m^{G}(\theta)\right)}{a\left(\theta, m^{G}(\theta)\right) c(h, 0)}=\left[\frac{L^{c}(\theta)+l^{t}(\theta, 0)}{L^{c}(\theta)+l^{g}\left(\theta, m^{G}(\theta)\right)}\right]^{1-\alpha} \frac{1+r_{T}(1-\psi)}{1+r_{T}}
$$

The right-hand-side of this is smaller than

$$
\left[\frac{L^{c}(\theta)+l^{t}(\theta, 0)}{L^{c}(\theta)+l^{g}\left(\theta, m^{G}(\theta)\right)} \frac{1+r_{T}(1-\psi)}{1+r_{T}}\right]^{1-\alpha}
$$

Therefore

$$
\left[\frac{a(\theta, 0) c\left(h, m^{G}(\theta)\right)}{a\left(\theta, m^{G}(\theta)\right) c(h, 0)}\right]^{\frac{1}{1-\alpha}}<\frac{L^{c}(\theta)+l^{t}(\theta, 0)}{L^{c}(\theta)+l^{g}\left(\theta, m^{G}(\theta)\right)} \frac{1+r_{T}(1-\psi)}{1+r_{T}}
$$

Combining this with (A34) we obtain

$$
1<\frac{p(\theta, 0)\left\{1+r_{T}(1-\psi)\right\}\left(L^{C}(\theta)+l^{t}(\theta, 0)\right)}{p\left(\theta, m^{G}(\theta)\right)\left\{1+r_{T}\right\}\left(L^{C}(\theta)+l^{g}\left(\theta, m^{G}(\theta)\right)\right)}
$$

Since $l^{g}\left(\theta, m^{G}(\theta)\right) \leq l^{t}(\theta, 0)$ we have $\frac{L^{c}(\theta)+l^{t}(\theta, 0)}{\left.L^{C}(\theta)+l^{g}\left(\theta, m^{G}(\theta)\right)\right)} \leq \frac{l^{t}(\theta, 0)}{\left.l^{g}\left(\theta, m^{G}(\theta)\right)\right)}$. So (A31) holds. 
Figure A1: Comparing selection in TRAIL and GRAIL villages. Descriptive Statistics on Productivity.

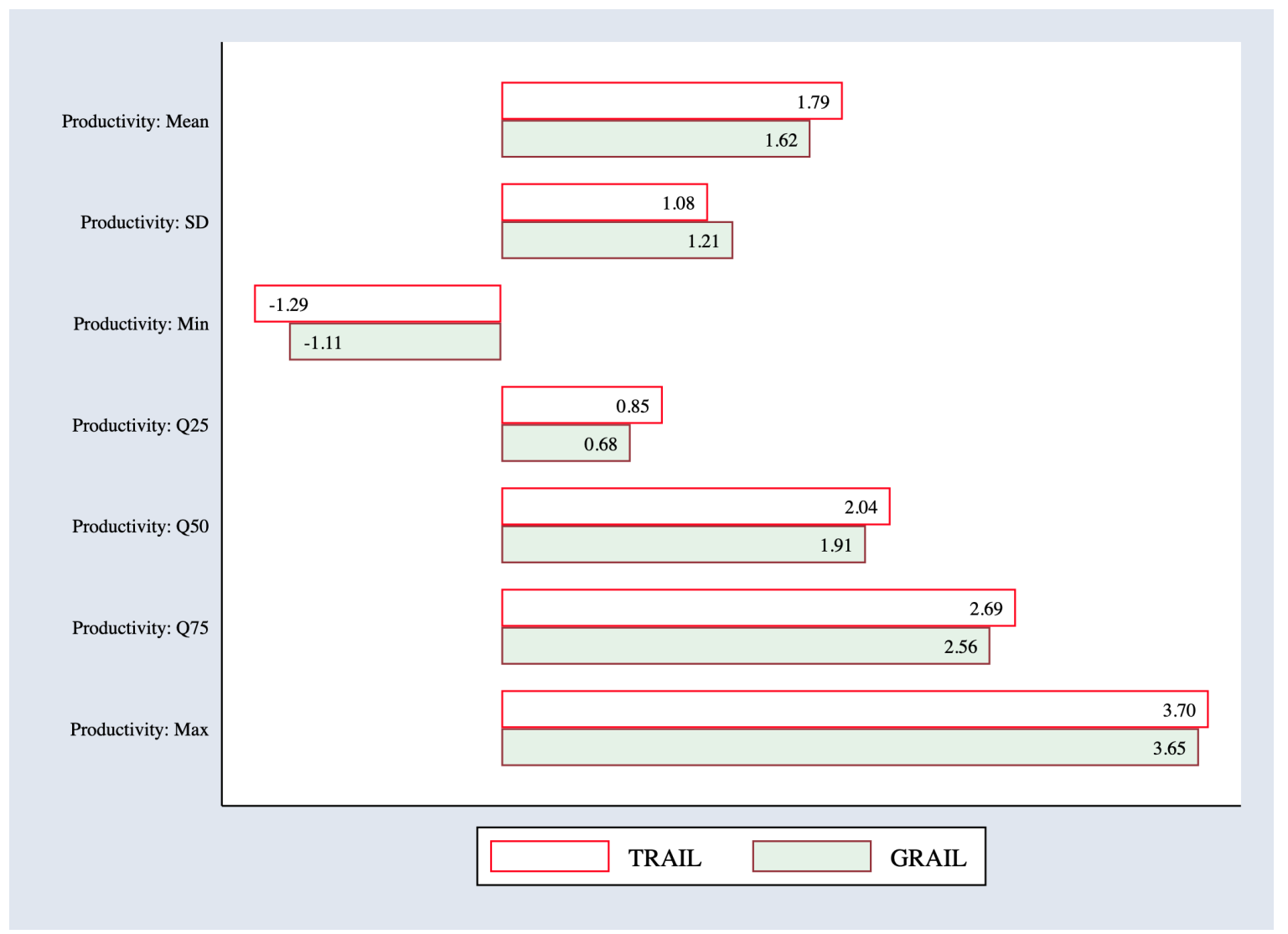

Notes: Sample restricted to Control 1 households TRAIL and GRAIL villages with at most 1.5 acres of land. 
Figure A2: Percentage of households in each Productivity Bin. TRAIL and GRAIL

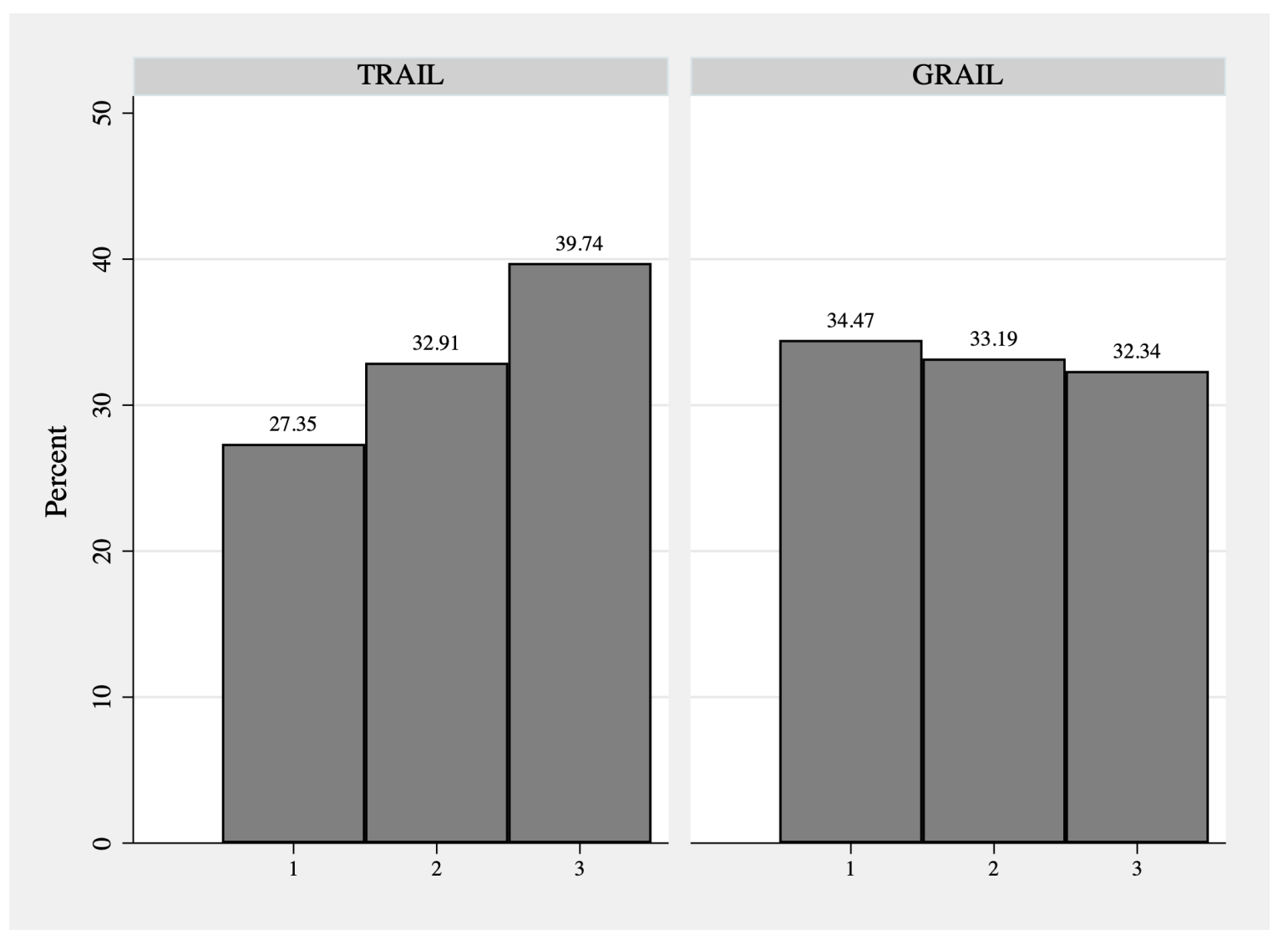

Notes: The height of the bars denote the fraction of households in each productivity Bin. Productivity is computed using the logarithm of acreage under potato cultivation. Sample restricted to Control 1 households in TRAIL and GRAIL villages with at most 1.5 acres of land. 
Figure A3: Variation in Farm Value Added for Treatment and Control 1 groups by Productivity
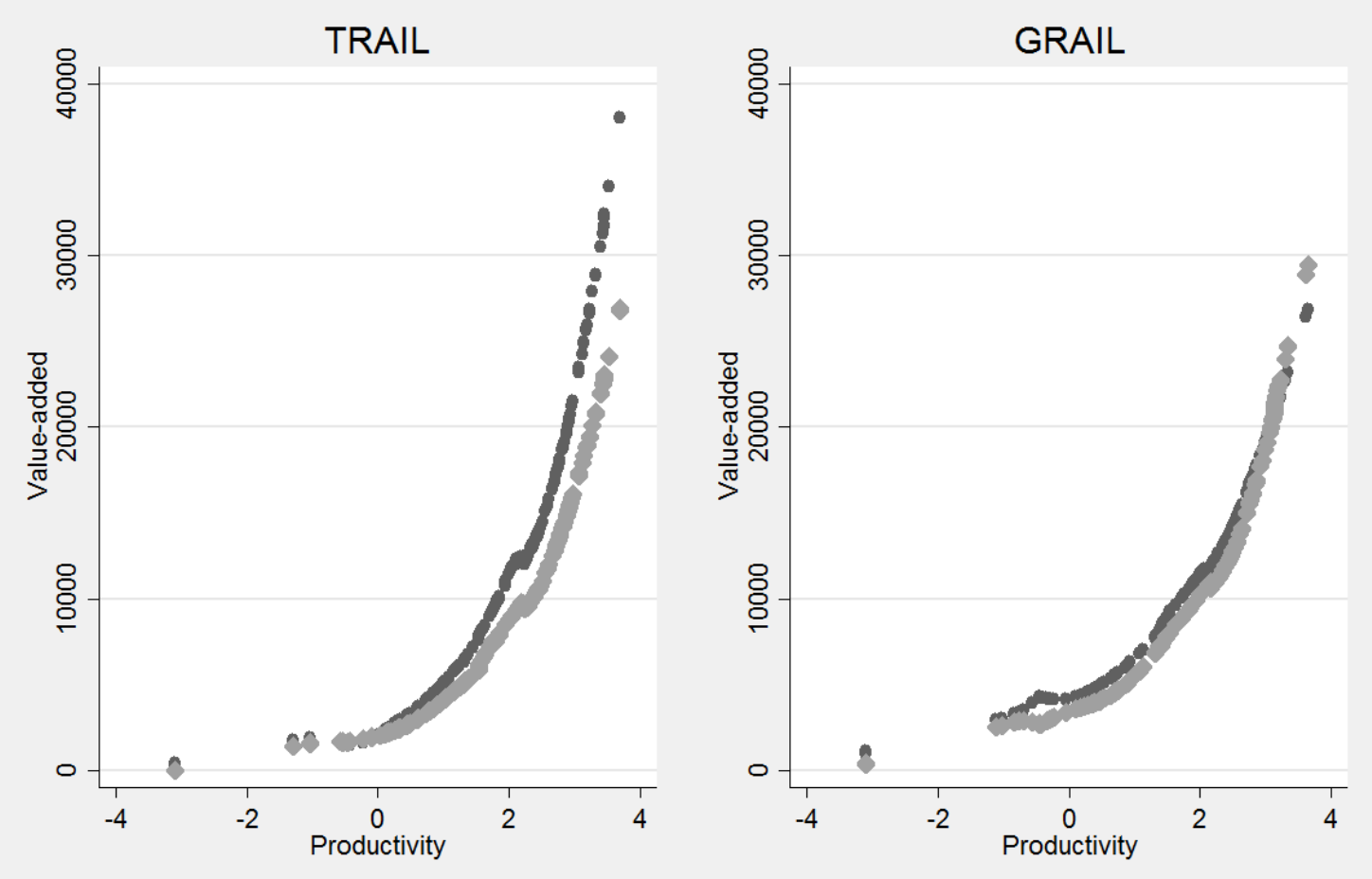

- Treatment group $\diamond$ Control 1 group

Notes: Lowess plot of farm value added from potato cultivation on productivity presented. Separate lowess plots presented for Treatment and Control1 households in TRAIL and GRAIL villages. 


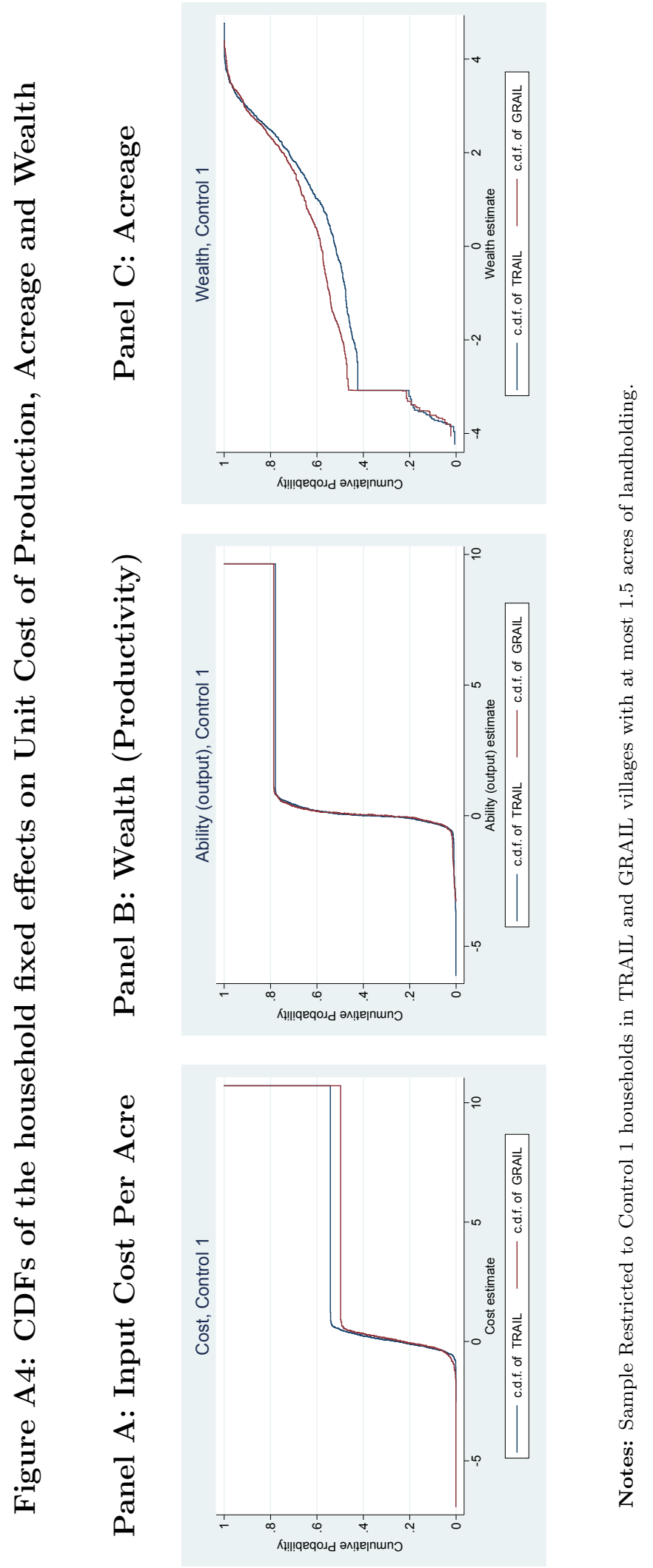




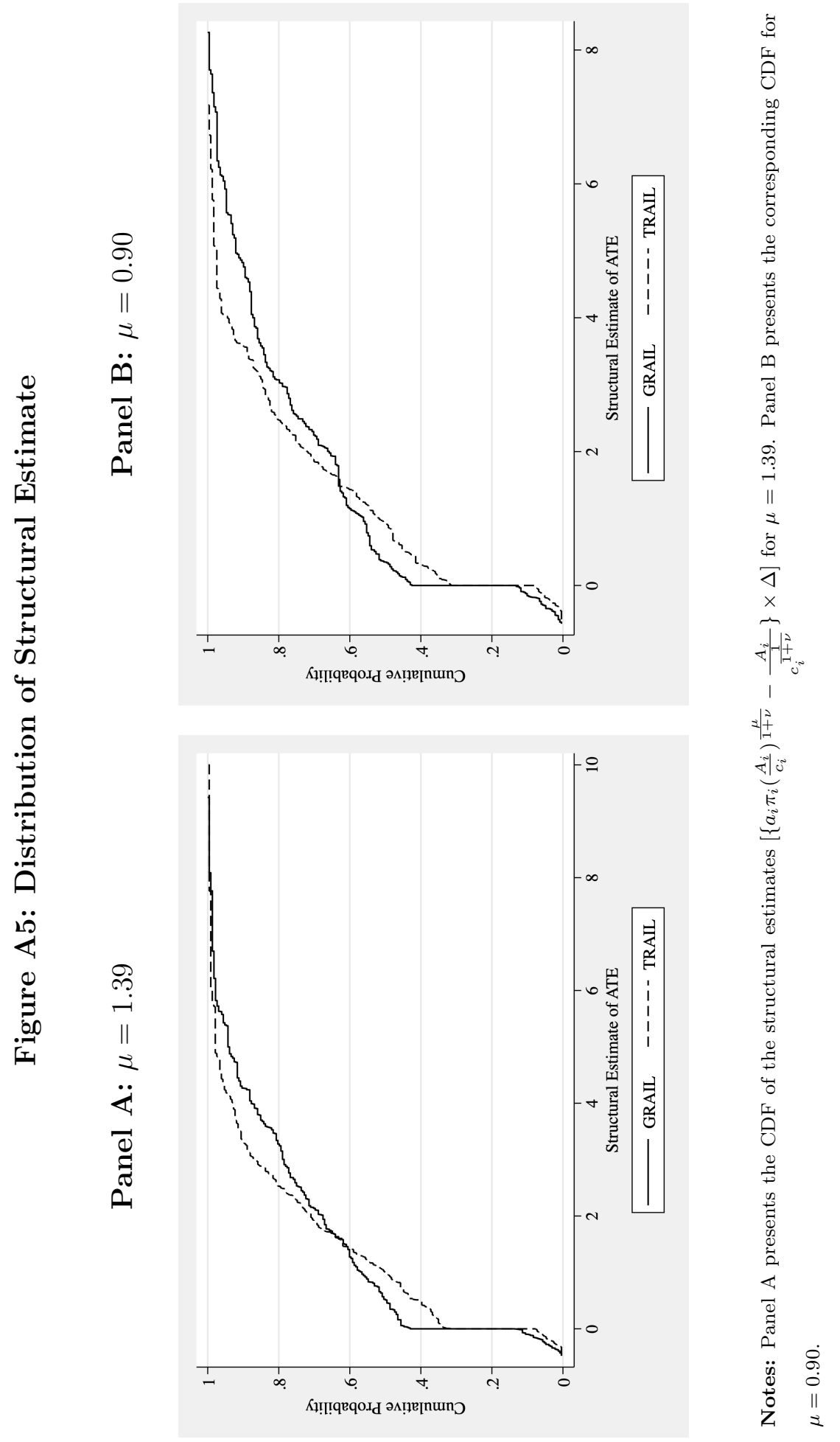




\section{Figure A6: Interest Rate on Informal Loans and Productivity. Control Households Only}

Panel A: Average Informal Interest Rates

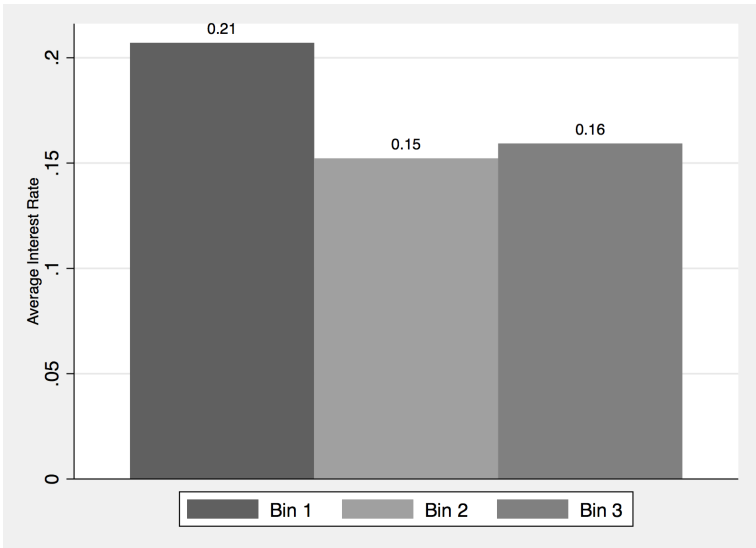

Panel B:

Variation in Informal Interest Rates

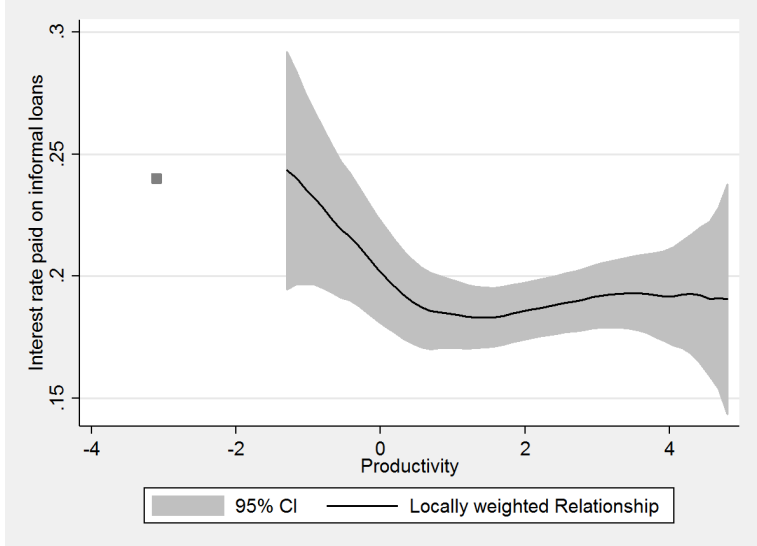

Notes: The vertical axis measures the average interest rate paid on informal loans by households. The horizontal axis shows the productivity estimate. In the left panel, we compute the average interest rate for households in each productivity bin. The average interest rate paid on informal loans by households in productivity Bin 1 is significantly higher than that paid by households in productivity Bin 2 ( $p-v a l u e=$ $0.03)$ and productivity Bin $3(p-$ value $=0.04)$. In the right panel we present the locally weighted regressions in of interest paid on informal loans on productivity. The average interest rate paid by households in productivity Bin 1 is shown as a single point. The sample is restricted to Control 1 and Control 2 households in TRAIL and GRAIL villages with at most 1.5 acres of land. Productivity is computed using the logarithm of the acreage under potato cultivation. 
Table A1: Baseline Credit Market characteristics

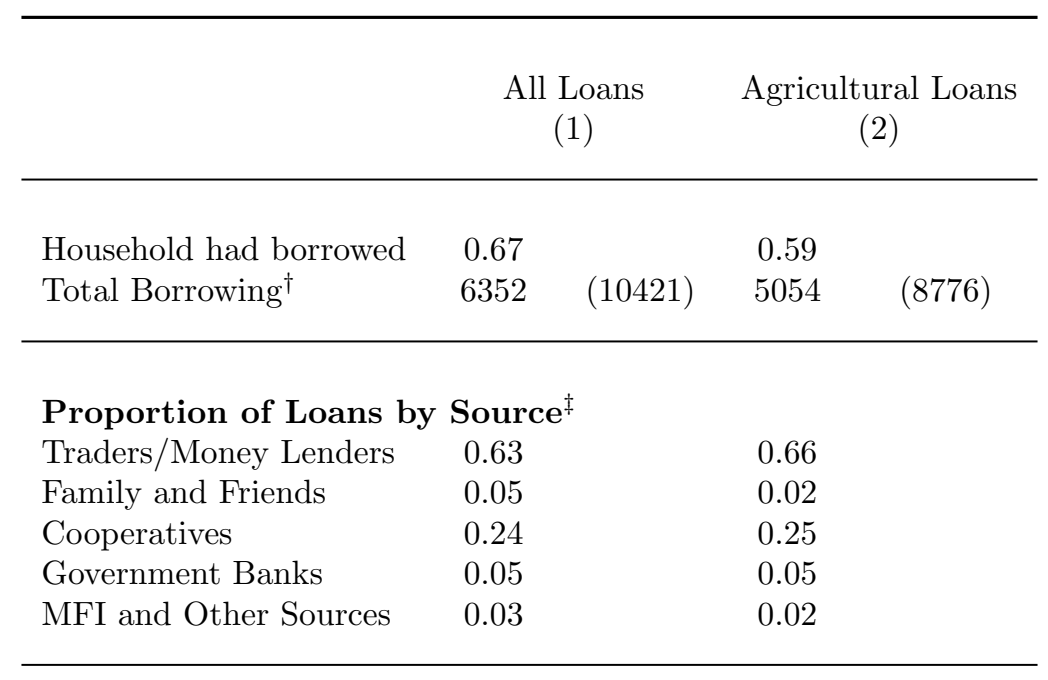

\begin{tabular}{lcccc}
\multicolumn{5}{l}{ Annualized Interest Rate by Source (percent) } \\
Traders/Money Lenders & 24.93 & $(20.36)$ & 25.19 & $(21.47)$ \\
Family and Friends & 21.28 & $(14.12)$ & 22.66 & $(16.50)$ \\
Cooperatives & 15.51 & $(3.83)$ & 15.70 & $(2.97)$ \\
Government Banks & 11.33 & $(4.63)$ & 11.87 & $(4.57)$ \\
MFI and Other Sources & 37.26 & $(21.64)$ & 34.38 & $(25.79)$
\end{tabular}

$\begin{array}{lcccc}\text { Duration by Source (days) } & & & \\ \text { Traders/Money Lenders } & 125.08 & (34.05) & 122.80 & (22.43) \\ \text { Family and Friends } & 164.08 & (97.40) & 183.70 & (104.25) \\ \text { Cooperatives } & 323.34 & (90.97) & 327.25 & (87.74) \\ \text { Government Banks } & 271.86 & (121.04) & 324.67 & (91.49) \\ \text { MFI and Other Sources } & 238.03 & (144.12) & 272.80 & (128.48)\end{array}$

$\begin{array}{lcr}\text { Proportion of Loans Collateralized by } & \text { Source } \\ \text { Traders/Money Lenders } & 0.02 & 0.01 \\ \text { Family and Friends } & 0.04 & 0.07 \\ \text { Cooperatives } & 0.79 & 0.78 \\ \text { Government Banks } & 0.81 & 0.83 \\ \text { MFI and Other Sources } & 0.01 & 0.01\end{array}$

Notes: Statistics are reported for all sample households in TRAIL and GRAIL villages with at most 1.5 acres of land. All characteristics are for loans taken by the households in Cycle 1. Program loans are not included. For the interest rate summary statistics loans where the principal amount is reported equal to the repayment amount are not included. To arrive at representative estimates for the study area, Treatment and Control 1 households are assigned a weight of $\frac{30}{N}$ and Control 2 households are assigned a weight of $\frac{N-30}{N}$, were $N$ is the total number of households in their village. ${ }^{\dagger}$ : Total borrowing $=0$ for households that do not borrow. $\ddagger$ : Proportion of loans in terms of value of loans at the household level. All proportions are computed only over households that borrowed. Standard deviations are in parentheses. 
Table A2: Cultivators and Non-cultivators. Differences in Demographic Characteristics

\begin{tabular}{lcc}
\hline & & \\
& $\begin{array}{c}\text { Non Cultivators } \\
(1)\end{array}$ & $\begin{array}{c}\text { Cultivators } \\
(2)\end{array}$ \\
\hline & & \\
Landholding & 0.267 & 0.561 \\
Non Hindu & 0.239 & 0.139 \\
Low Caste & 0.419 & 0.261 \\
Household Size & 4.440 & 4.806 \\
Female Headed Household & 0.101 & 0.031 \\
Age of Oldest Male & 45.280 & 49.007 \\
Oldest Male: Completed Primary School & 0.348 & 0.457 \\
\hline
\end{tabular}

Notes: Households that cultivate potato at least 2 of the 3 survey years are categorized as cultivators. 


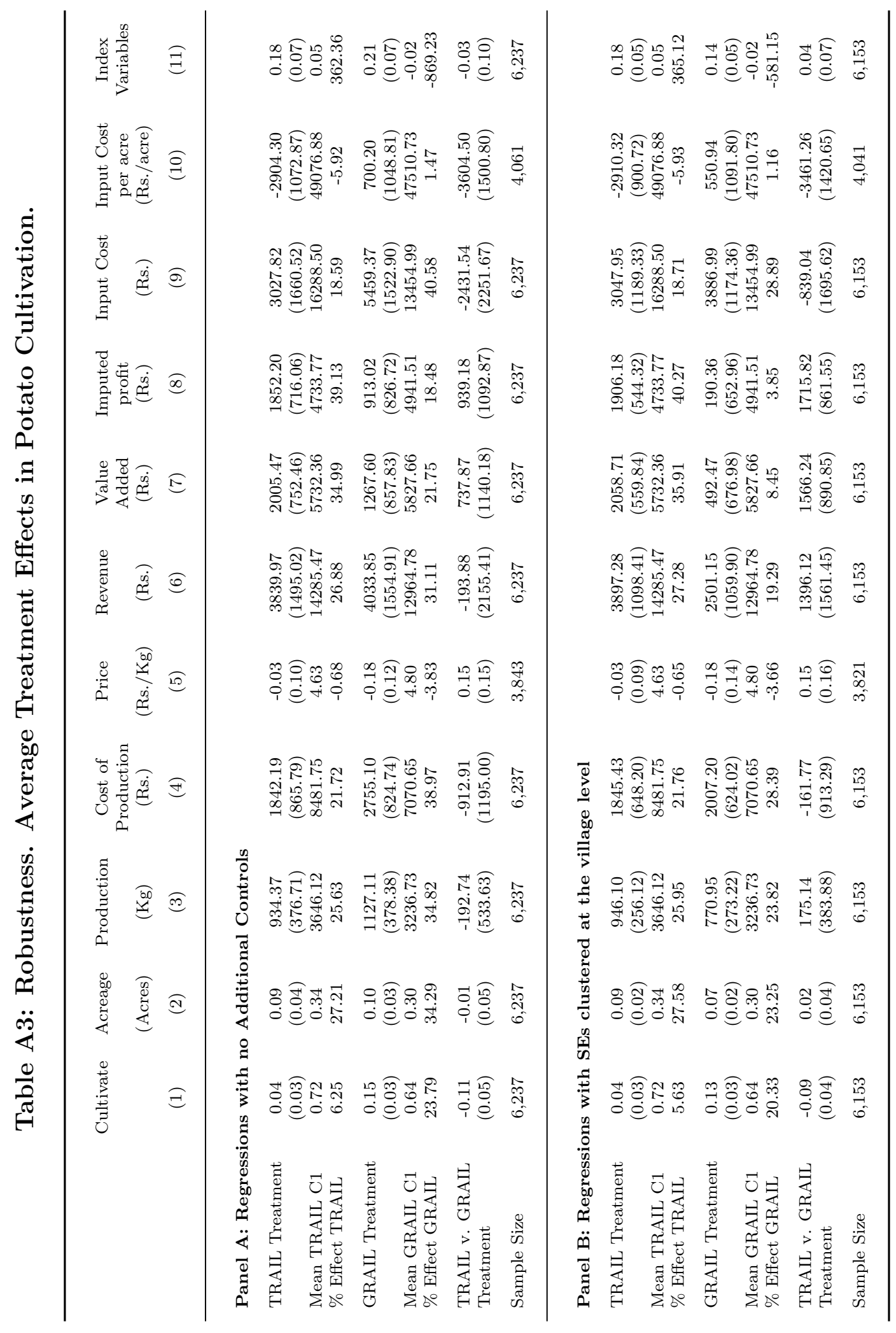




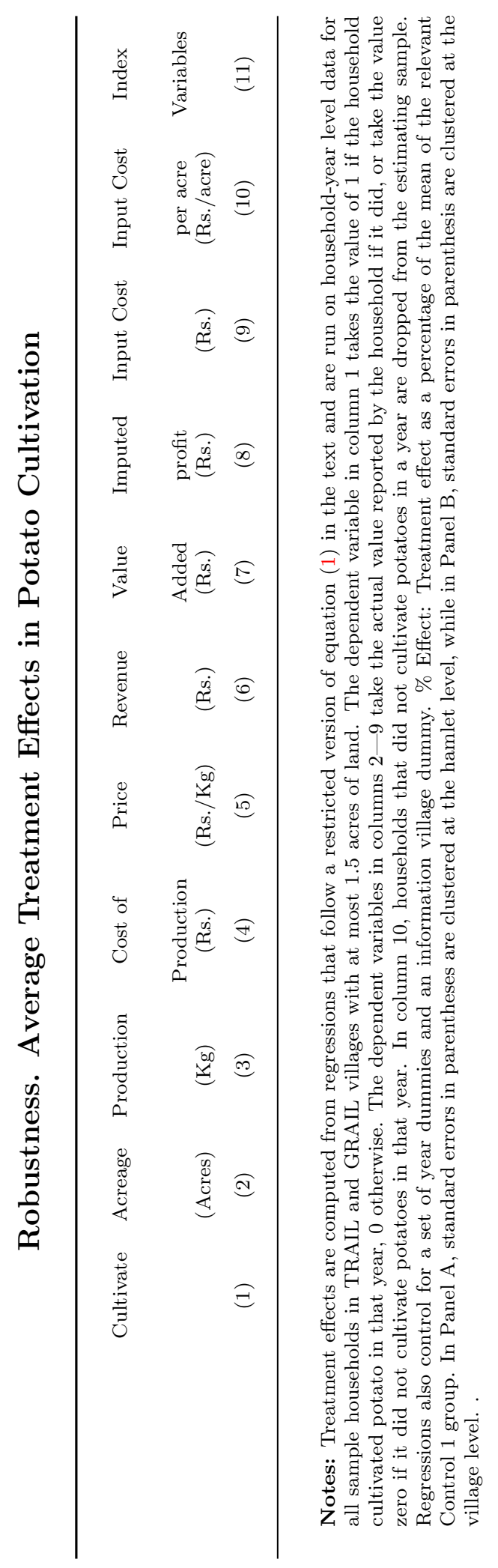

